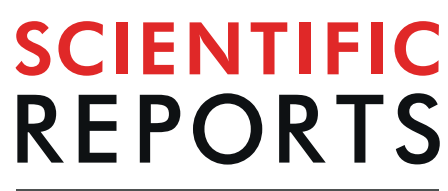

natureresearch

Check for updates

\title{
Core Binding Factors are essential for ovulation, luteinization, and female fertility in mice
}

Somang Lee-Thacker ${ }^{1}$, Hayce Jeon ${ }^{1}$, Yohan $\mathrm{Choi}^{1}{ }^{1}$ Ichiro Taniuchi ${ }^{2}$, Takeshi Takarada ${ }^{3}$, Yukio Yoneda ${ }^{4}$, CheMyong $\mathrm{Ko}^{5}$ \& Misung Jo ${ }^{1 凶}$

Core Binding Factors (CBFs) are a small group of heterodimeric transcription factor complexes composed of DNA binding proteins, RUNXs, and a non-DNA binding protein, CBFB. The LH surge increases the expression of Runx 1 and Runx 2 in ovulatory follicles, while $C b f b$ is constitutively expressed. To investigate the physiological significance of $\mathrm{CBFs}$, we generated a conditional mutant mouse model in which granulosa cell expression of Runx2 and $C b f b$ was deleted by the Esr2Cre. Female Cbfb flox/flox; Esr $2^{\text {cre/ }+} ;$ Run $2^{\text {floxfflox }}$ mice were infertile; follicles developed to the preovulatory follicle stage but failed to ovulate. RNA-seq analysis of mutant mouse ovaries collected at $11 \mathrm{~h}$ post-hCG unveiled numerous CBFs-downstream genes that are associated with inflammation, matrix remodeling, wnt signaling, and steroid metabolism. Mutant mice also failed to develop corpora lutea, as evident by the lack of luteal marker gene expression, marked reduction of vascularization, and excessive apoptotic staining in unruptured poorly luteinized follicles, consistent with dramatic reduction of progesterone by $24 \mathrm{~h}$ after $\mathrm{hCG}$ administration. The present study provides in vivo evidence that $\mathrm{CBFs}$ act as essential transcriptional regulators of both ovulation and luteinization by regulating the expression of key genes that are involved in inflammation, matrix remodeling, cell differentiation, vascularization, and steroid metabolisms in mice.

Successful ovulation and subsequent development of the corpus luteum (CL) are fundamental for female fertility. The luteinizing hormone (LH) surge initiates these processes by activating responsive second messengers in preovulatory follicle cells. The activation of these second messenger systems leads to the induction and activation of transcriptional regulators that directly control the expression of a diverse array of genes encoding intra- and extra-cellular factors [reviewed in ${ }^{1,2}$. These factors execute precisely coordinated actions to accomplish successful ovulation and subsequent development of the CL. Accumulating evidence using transgenic mouse models has identified such transcription factors including progesterone receptor (PGR), CCAAT/enhancer-binding protein alpha/beta (CEBPA/B), peroxisome proliferator-activated receptor $\gamma$ (PPARG), the liver receptor homolog-1 (NR5A2), and nuclear receptor-interacting protein 1 (NRIP1) ${ }^{3-7}$. Recent studies by our and other laboratories have shed light on a small family of transcription factors, the Core Binding Factors (CBFs), as critical mediators of the periovulatory process ${ }^{8-10}$.

The CBF is a heterodimeric transcription factor complex composed of DNA binding alpha subunits (RUNX1, RUNX2, and RUNX3) and a non-DNA binding beta subunit (CBFB). CBFs play fundamental roles in tissue development, with each RUNX protein playing a distinct role(s) in the development of various tissues ${ }^{11-15}$. As a partner for all RUNX proteins, CBFB has shown to enhance the DNA binding activity and stability of RUNX proteins, thus is instrumental in the overall activity of CBFs ${ }^{16-18}$.

In the ovary, the LH surge increases the expression of Runx 1 and Runx2 in preovulatory follicles, while Cbfb is ubiquitously and constitutively expressed ${ }^{9,19-21}$. Functional redundancy among RUNX proteins has been reported

${ }^{1}$ Department of Obstetrics and Gynecology, Chandler Medical Center, 800 Rose Street, University of Kentucky, Lexington, KY, 40536-0298, USA. ${ }^{2}$ Laboratory for Transcriptional Regulation, RIKEN Center for Integrative Medical Sciences 1-7-22, Suehiro-cho, Tsurumi-ku, Yokohama, Kanagawa, 230-0045, Japan. ${ }^{3}$ Department of Regenerative Science, Okayama University Graduate School of Medicine, Dentistry and Pharmaceutical Sciences, Okayama, 700-8558, Japan. ${ }^{4}$ Section of Prophylactic Pharmacology, Kanazawa University, Venture Business Laboratory 402, Kakuma-machi, Kanazawa, Ishikawa, 920-1192, Japan. ${ }^{5}$ Department of Comparative Biosciences, College of Veterinary Medicine, 2001 South Lincoln Avenue, University of Illinois at Urbana-Champaign, Urbana, Illinois, 61802,

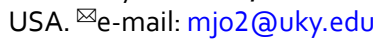


in cancer cells as well as normal cells ${ }^{22,23}$. In the previous study using rat granulosa cells, we also showed that RUNX1 and RUNX2 have a redundant function in regulating the expression of Hapln $1^{24}$. In addition, evidence from in vivo and in vitro studies showed that RUNX2 down-regulated Runx1 expression in forming CL in rats and mice ${ }^{10,25}$, indicating a cross-regulation between different family members in ovarian cells. Moreover, mice deficient of the Runx1, Runx2, or Cbfb gene die at the embryonic stage or shortly after birth ${ }^{12,13,26}$. These findings present challenges in determining the role of each RUNX protein as well as the functional significance of overall CBFs in the adult ovary in vivo.

Recently, we generated granulosa cell-specific Cbfb knockout mice using two different Cre lines (Cyp19 $9^{\text {cre }}$ and $\left.E s r 2^{C r e /+}\right)^{9,10}$. Our rationale was to reduce the activity of both RUNX1 and RUNX2 by deleting Cbfb expression in granulosa cells. Both transgenic mouse lines were subfertile ${ }^{9,10}$, with $C b f b^{f l o x / f l o x} ; E s r 2^{C r e /+}$ mice displaying stronger phenotypical changes compared to those of $C b f b^{\text {flox/flox}}$; $C y p 19 a 1^{\text {cre }}$ mice ${ }^{9,10}$. In agreement with these findings, $C b f b^{f l o x} / f l o x ; E s r 2^{C r e /+}$ mice showed higher efficiency in deleting $C b f b$ expression in granulosa cells than Cbfb flox/flox; Cyp $19^{\text {cre }}$ mice ${ }^{9,10}$. This might be in part due to the timing difference in Esr2 and Cyp19a1 expression in primary vs. secondary follicles, respectively, or incomplete removal of the gene by Cyp19-Cre throughout all follicles ${ }^{27,28}$. Despite severe subfertility, $C b f b^{f l o x / f l o x} ; E s r 2^{C r e /+}$ mice showed only $\sim 65 \%$ reduction in ovulation rates, and the majority of unruptured antral follicles transformed into morphologically normal-looking CL, although progesterone levels were reduced on day 3 post-hCG administration compared to those in wild-type animals ${ }^{10}$. Consistent with these changes, the expression of two ovulatory genes (Edn2 and Ptgs1) and several luteal genes (Lhcgr, Sfrp4, Wnt4, Ccrl2, Lipg, Saa3, and Ptgfr) was compromised in these mutant mouse lines ${ }^{9,10}$. These data indicated that the deletion of $C b f b$ in granulosa cells resulted in a partial reduction of ovulation rate and CL function in mice.

In establishing granulosa cell-specific $C b f b$ knockout mice, we presumed that $C b f b$ deletion would result in the greatly diminished activity and degradation of RUNX proteins. For RUNX1 protein, this was true in ovulatory follicles ${ }^{10}$. However, the LH surge/hCG-induced expression of Runx2 (mRNA and protein) was not affected in the

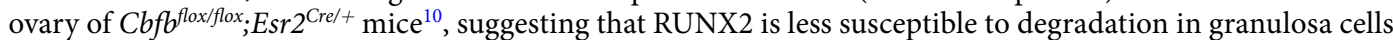
and may function even in the absence of CBFB. Therefore, it is important to determine whether the additional deletion of Runx 2 would result in more profound defects in ovulation and luteal development.

To address this question, we generated transgenic mice deficient of both the Runx2 and Cbfb gene in granulosa cells $\left(\mathrm{Cbfb} f^{f l o x} / f l o x ; E s r 2^{C r e /+} ;\right.$ Run $\left.x 2^{\text {flox/flox }}\right)$. This mutant mouse was used to assess ovulation rate, CL development, gene expression, ovarian morphology, hormone profiles, and fertility. Herein, we demonstrated that the removal of RUNX1, RUNX2, and CBFB in periovulatory granulosa cells resulted in a complete blockage of ovulation and CL development in the mouse ovary, consequently causing infertility. This study also identified a number of additional genes that are potential downstream targets of RUNXs/CBFB, which are involved in the ovulatory process and luteinization in the mouse ovary.

\section{Results}

Generation and verification of granulosa cell-specific double deletion of Cbfb and Runx2 in mice. Female $C b f b^{f l o x / f l o x} ; E s r 2^{C r e /+}$ mice were subfertile ${ }^{10}$. Therefore, to generate a mutant mouse line bear-

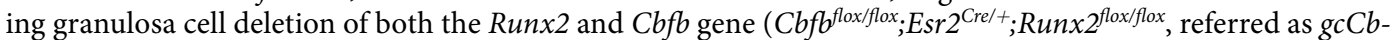
$f b ; R u n x 2 K O)$, the breeding scheme depicted in Fig. 1A was used by first mating female Runx $2^{\text {flox/flox }}$ with male $C b f b^{f l o x} f f l o x ; E s r 2^{C r e /+}$ mice. To verify the ablation of $C b f b$ and Runx2 expression, granulosa cells were isolated from ovaries of immature mice at $11 \mathrm{~h}$ after hCG administration. The levels of mRNA for Runx 2 and $C b f b$, but not for Runx 1, were drastically reduced in $g c C b f b ; R u n x 2 K O$ mice compared to Run $x 2^{\text {floxfflox}}$;Cbfb floxflox (wild-type) mice (Fig. 1B). Similarly, RUNX2 and CBFB were undetectable in granulosa cells of $g c C b f b$;Runx2KO mice (Fig. 1C). Immunohistochemical analyses further confirmed the ablation of RUNX2 in preovulatory follicles of the double KO mice (Fig. 1D-d). In addition, little staining for RUNX1 was detected in the preovulatory follicles of this mutant mouse (Fig. 1D-b). This is consistent with a previous report showing that in the absence of $C b f b$, RUNX1 protein became unstable and was likely ubiquitinated in granulosa cells of periovulatory follicles ${ }^{10}$. These data confirmed the deletion of Runx2 and Cbfb as well as the loss of RUNX1 protein in granulosa cells of preovulatory follicles in mutant mice.

gcCbfb;Runx2KO mice are infertile and display disturbed estrous cycles. To determine the reproductive capacity, female wild-type and $g c C b f b ; R u n x 2 \mathrm{KO}$ mice at two months of age were subjected to a fertility test by mating with males of proven fertility at least for three months (Fig. 1E). None of the double KO mice produced pups, while wildtype animals were all fertile. After the end of the breeding trial, these animals were subjected to daily vaginal cytology for at least two cycles. The double KO mice stayed longer in estrus (marked as $\mathrm{E}$, the presence of predominantly cornified epithelial cells) than wild-type mice ( $72 \% \mathrm{vs} .37 \%$ ), indicative of irregular estrous cycles (Fig. 1F). Of note, the breeding scheme used (Fig. 1A) also produced mutant mice deficient

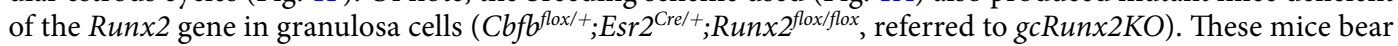
a heterozygous deletion of $C b f b$ in granulosa cells. $g c R u n x 2 K O$ mice showed complete ablation of RUNX2 but displayed the normal expression of RUNX1 in granulosa cells of periovulatory follicles (Supplementary Fig. 1A). These mutant mice displayed the subfertility phenotype; three out of six female mice that were mated with fertile males became pregnant and/or delivered pups (3, 4, 6 pups for each), while the remaining three did not show any sign of pregnancy during the 2 months trial period (Supplementary Fig. 1B).

gcCbfb;Runx2KO mice failed to ovulate. To determine whether the ovulatory capacity was compromised in mutant mice, ovulation rates and ovarian morphology were assessed using both superovulation-induced immature mice and unstimulated adult animals. The ovulation-induced model allowed us to bypass potential impacts of Esr2 Cre expression in non-ovarian tissues (e.g., hypothalamus/pituitary). Examination of the oviduct 
A)

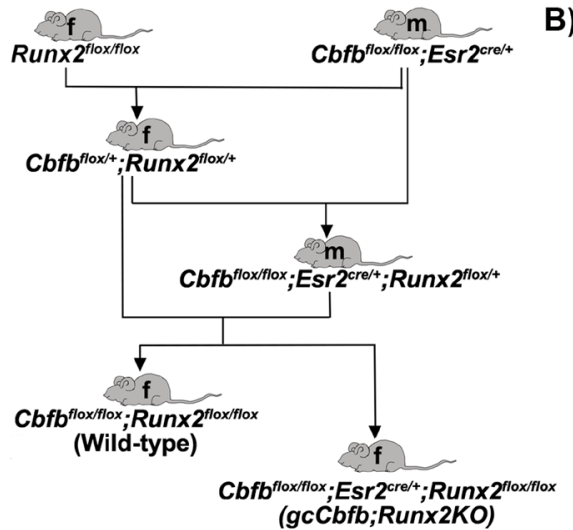

C)

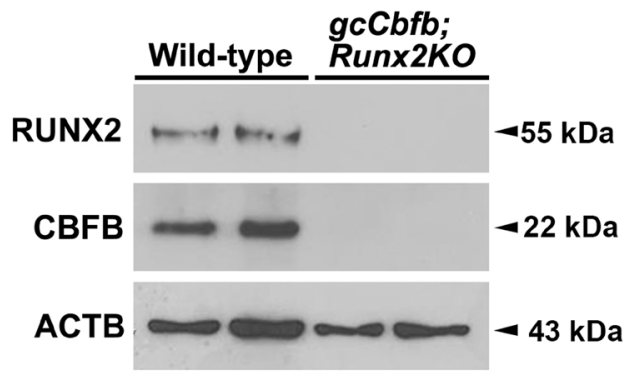

B)

D)
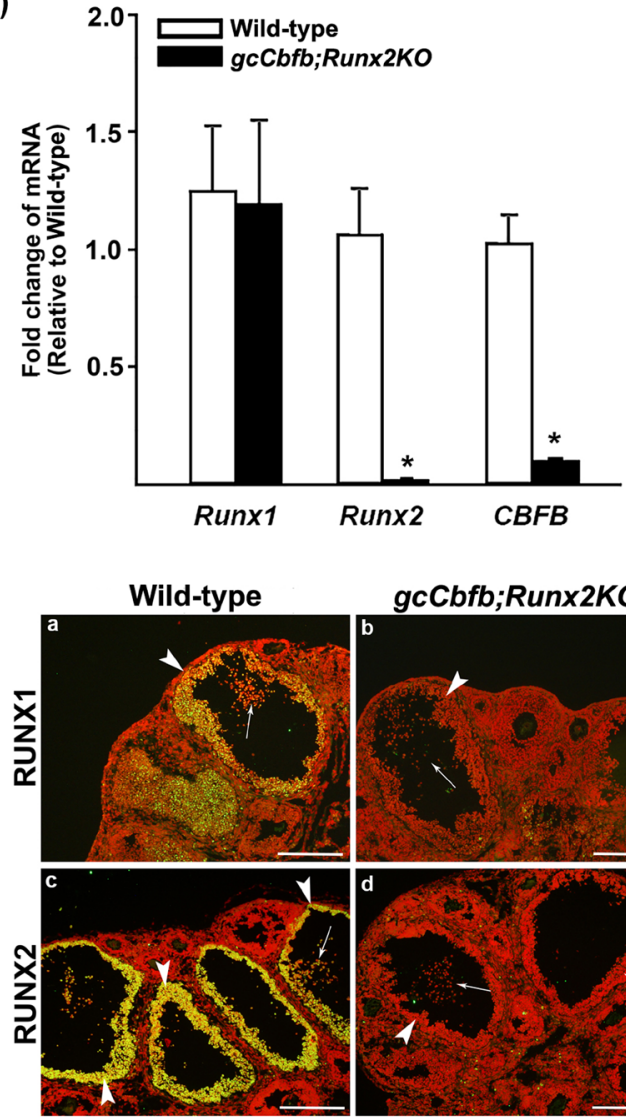

gcCbfb;Runx2KO

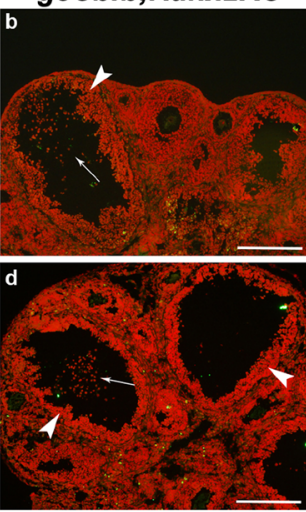

E)

\begin{tabular}{ccccc}
\hline Genotype & n & Fertility & \# of pups/litter & \# of litters for $\mathbf{3}$ months \\
\hline Wild-type & 9 & $100 \%$ & $8.3 \pm 0.5$ & $2.5 \pm 0.17$ \\
\hline gcCbfb;Runx2KO & 9 & $0 \%$ & 0 & 0 \\
\hline
\end{tabular}

F)

\begin{tabular}{|c|c|c|c|c|c|c|c|c|c|c|c|}
\hline Genotype Day & 1 & 2 & 3 & 4 & 5 & 6 & 7 & 8 & 9 & 10 & 11 \\
\hline Wild-type & $\mathrm{E}$ & & & & $\mathrm{E}$ & $\mathrm{E}$ & & & & $\mathrm{E}^{*}$ & \\
\hline Wild-type & $\mathrm{E}$ & $\mathrm{E}$ & & & & $\mathrm{E}$ & & & & $\mathrm{E}^{*}$ & \\
\hline Wild-type & $\mathrm{E}$ & & & & $\mathrm{E}$ & & & & $\mathrm{E}^{*}$ & & \\
\hline Wild-type & & $\mathrm{E}$ & $\mathrm{E}$ & & & & $\mathrm{E}$ & & & & $\mathrm{E}^{*}$ \\
\hline gcCbfb;Runx2KO & $\mathrm{E}$ & $\mathrm{E}$ & & $\mathrm{E}$ & $\mathrm{E}$ & $\mathrm{E}$ & & $\mathrm{E}$ & $\mathrm{E}$ & & $\mathrm{E}^{*}$ \\
\hline gcCbfb;Runx2KO & $\mathrm{E}$ & $\mathrm{E}$ & $\mathrm{E}$ & & $\mathrm{E}$ & $\mathrm{E}$ & $\mathrm{E}$ & $\mathrm{E}$ & & $\mathrm{E}^{*}$ & \\
\hline gcCbfb;Runx2KO & & $\mathrm{E}$ & $\mathrm{E}$ & & $\mathrm{E}$ & $\mathrm{E}$ & $\mathrm{E}$ & & $\mathrm{E}^{*}$ & & \\
\hline gcCbfb;Runx2KO & $\mathrm{E}$ & $\mathrm{E}$ & $\mathrm{E}$ & & $\mathrm{E}$ & $\mathrm{E}$ & $\mathrm{E}$ & & & $\mathrm{E}^{*}$ & \\
\hline
\end{tabular}

Figure 1. Cbfb flox/flox; Esr $2^{\text {cre/t+}} ;$ Runx $2^{\text {flox/flox }}(g c C b f b ; R u n x 2 K O)$ mice: Generation and verification of ovarian ablation of Runx2 and $C b f b$ expression and assessment of fertility and estrous cycling pattern. (A) Breeding schemes used

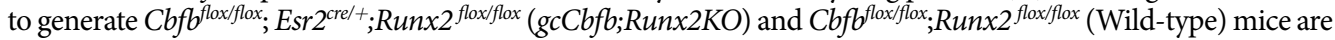
depicted. $\mathrm{F}$ and $\mathrm{M}$ in the shape of mice represent female and male, respectively. (B) Granulosa cells were isolated from ovaries collected at $11 \mathrm{~h}$ post-hCG from PMSG-primed immature mice. Levels of mRNA for Runx1, Runx2, and Cbfb were measured by qPCR and normalized to the $R p l 19$ value in each sample ( $\mathrm{n}=8$ animals/genotype). $* p<0.0001$. (C) Western blot detection of RUNX2 and CBFB proteins in granulosa cells isolated at $11 \mathrm{~h}$ post-hCG. The membrane was re-probed with a monoclonal antibody against beta-actin (ACTB) to assess the loading of protein in each lane $(\mathrm{n}=2$ animals/genotype). (D) Immunohistochemical detection of RUNX1 and RUNX2 in ovaries of control and mutant mice collected at $11 \mathrm{~h}$ post-hCG $(\mathrm{n}=3$ animals/genotype). Immune-positive staining for RUNX1 or RUNX2 proteins (yellow/green) was localized to granulosa cells of periovulatory follicles in wild-type mice. Arrowheads and arrows point to granulosa cells and cumulus cells of preovulatory follicles, respectively. The sections were counterstained with propidium iodide (red) for nuclear staining. Scale bars, $250 \mu \mathrm{m}$ for all images. (E) At 2 months of age, wild-type and $g c C b f b$;Runx $2 \mathrm{KO}$ mice were mated with fertile males for 3 months. (F) Estrus cyclicity was monitored by daily vaginal smears for at least 2 cycles, and the presence of predominantly cornified cells was labeled as $\mathrm{E}$ (estrus). The animals were euthanized in the morning of estrus and marked $\mathrm{E}^{*}$. 

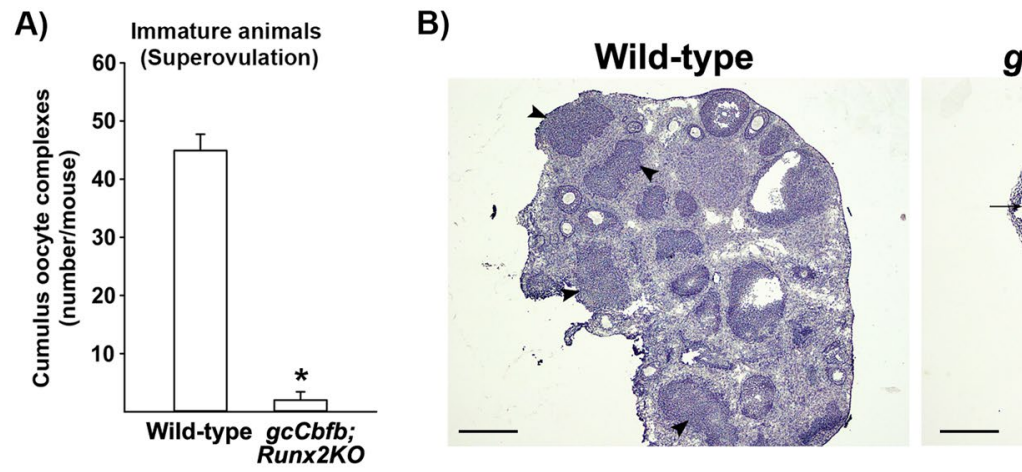

gcCbfb;Runx2KO

C)

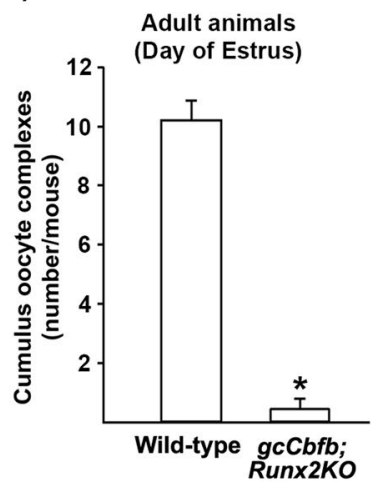

D)

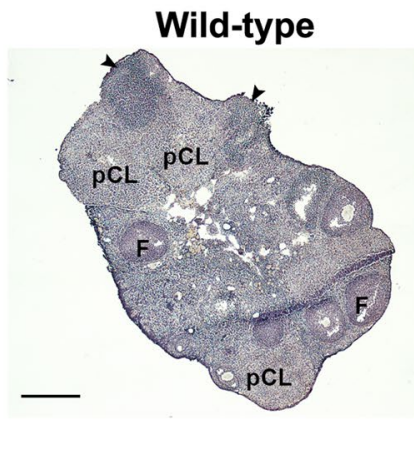

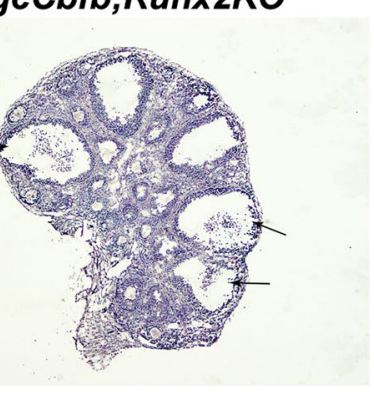

.

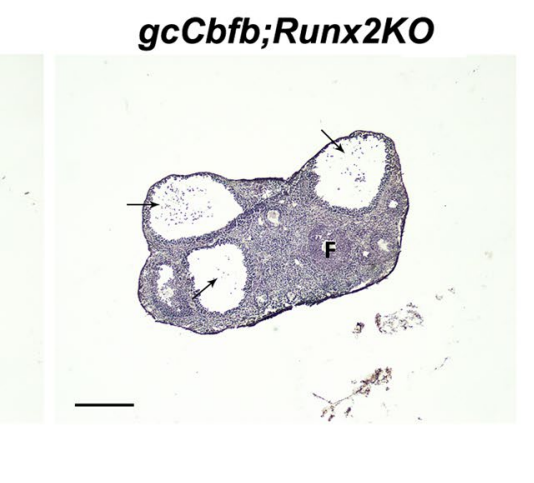

Figure 2. $g c C b f b$;Run $x 2 K O$ mice failed to ovulate. (A \& B) Immature wild-type and $g c C b f b$; Run $x 2 K O$ mice primed with PMSG/hCG were killed between 16-24h after hCG administration and cumulus oocyte complexes (COCs) were collected from oviducts and counted (A), and their ovarian morphology was examined (B) $\left(\mathrm{n}=13\right.$ and 8 for control and mutant mice, respectively). ${ }^{*} p<0.001$. (C \& D) Adult mice were euthanized in the morning of estrus (marked as $E^{*}$ in Fig. 1F). COCs were collected from oviducts and counted $(\mathbf{C})$, and their ovarian morphology was examined (D) ( $\mathrm{n}=5$ and 9 for control and mutant mice, respectively). $* p<0.001$. Arrows and arrowheads point to large antral follicles with expanded cumulus cells and newly forming CL, respectively. pCL; CL generated from previous cycles. F; follicle. Scale bars, $500 \mu \mathrm{m}$ for all images.

of superovulation-induced mice showed significantly lower numbers of oocytes released in double knockout mice ( 6 out of 8 mice had no COCs) compared to that in wild-type animals (Fig. 2A). Histology of the ovary obtained $16 \mathrm{~h}$ post-hCG showed the presence of expanded cumulus cells and oocytes entrapped in large follicles in the double KO mice (Fig. 2B), whereas the ovary of wild-type animals displayed many newly forming CLs. The ovulation rate was also reduced ( 70\%) in gcRunx2KO mice compared to wild-type animals (Supplementary Fig. 1C). Ovaries of $g c R u n x 2 \mathrm{KO}$ mice displayed multiple large follicles with entrapped COCs as well as forming CLs after superovulation-induction (Supplementary Fig. 1D).

For adult animals, their ovaries and oviducts were collected in the morning (between 1100 to $1200 \mathrm{~h}$ ) of estrus (marked as $\mathrm{E}^{*}$ in Fig. 1F). This is the time point when oocytes can be collected in the oviduct because ovulation typically occurs in the early morning of estrus, and newly formed CLs can be easily identified histologically in the ovary. As expected, an average of 10 oocytes was collected in oviducts of wild-type animals, whereas $g c C b$ $f b$;Run $x 2 \mathrm{KO}$ mice had only a few oocytes if any in the oviduct ( 7 out of 9 mice had no COCs)(Fig. 2C). As expected, in wild-type animals, multiple newly forming CLs, as well as CLs generated from previous cycles, were found in the ovary (Fig. 2D). Meanwhile, the double KO mice showed multiple large antral follicles, some of them with entrapped COCs, but no CL (Fig. 2D). These differences were strikingly similar to those observed with the superovulation model, indicating that the infertility phenotype of mature double KO mice was mainly caused by anovulation and failure to develop functional CL.

Identification of genes whose expression was affected in the gcCbfb;Runx2KO mouse ovary. To determine the mechanisms causing impaired ovulation in mutant mice, ovaries of immature animals collected at 3 and $11 \mathrm{~h}$ post-hCG were used to analyze the expression of key ovulatory genes. These time points were selected to determine whether anovulatory phenotype was caused by defects in early ovulatory response (e.g., failure to respond to hCG/LH stimulation) or late ovulatory events via assessing early and late changes in gene expression, respectively. The levels of mRNA for Areg, Ereg, Fos, Pgr, and Ptgs2 were compared between control and mutant mouse ovaries obtained at $3 \mathrm{~h}$ post-hCG. We selected these genes as hCG rapidly induces their expressions in preovulatory follicles within a few hours ${ }^{4,29,30}$. Moreover, these genes are known to be critical for ovulation ${ }^{4,29,30}$. 
A)

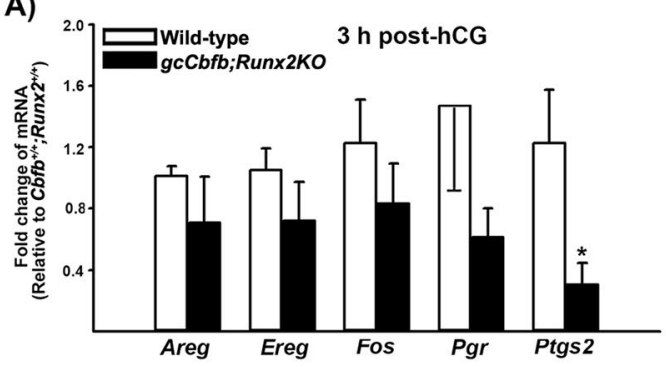

C) PgrmRnA

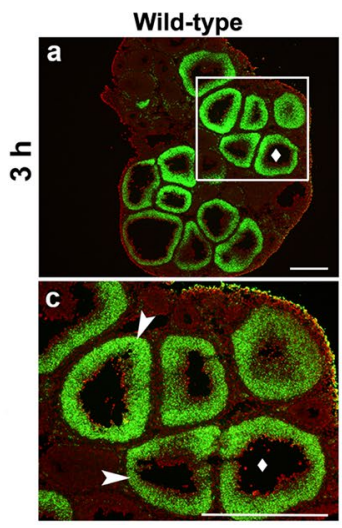

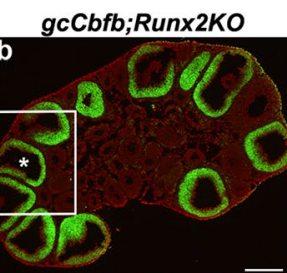

d

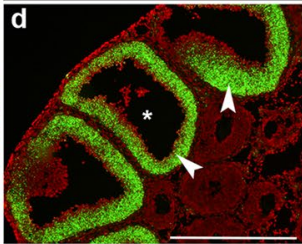

B)

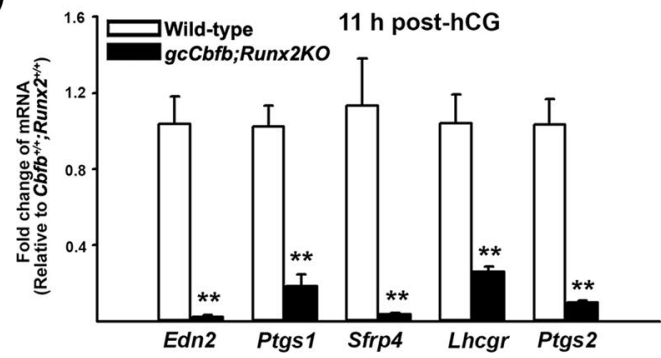

D) Ptgs 2 mRNA

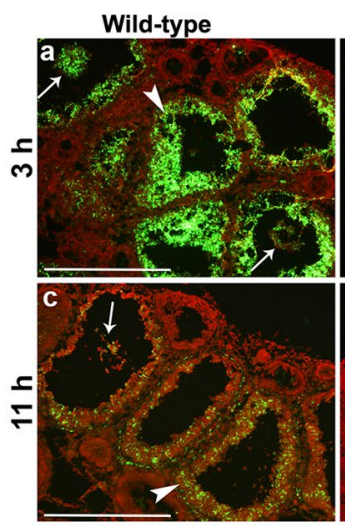

Figure 3. The differential expression of key early and late ovulatory genes in ovaries of $g c C b f b$; Runx2KO mice. (A) Ovaries were collected at $3 \mathrm{~h}$ after hCG administration. The levels of mRNA for early ovulatory genes were measured by qPCR, normalizing to the Rpl19 value in each sample ( $\mathrm{n}=7$ and 6 for control and mutant mice, respectively). ${ }^{*} p<0.05$. (B) Ovaries were collected at $11 \mathrm{~h}$ after hCG administration. The levels of mRNA for late ovulatory genes were measured by qPCR, normalizing to the $R p l 19$ value in each sample $(\mathrm{n}=8$ and 7 for control and mutant mice, respectively). **p<0.01. (C \& D) The localization of Pgr mRNA and Ptgs 2 mRNA was evaluated via in situ hybridization analyses in ovaries collected at 3 and $11 \mathrm{~h}$ post-hCG ( $\mathrm{n}=3$ /genotype). Green fluorescence staining represents transcripts for these genes. The tissue sections were counterstained with propidium iodide (red). Arrowheads and arrows point to granulosa cells of preovulatory follicles and expanded cumulus cells, respectively. Scale bars, $500 \mu \mathrm{m}$ for all the images.

The levels of mRNA for Areg, Ereg, Fos, and Pgr were not different between wild-type mice and $g c C b f$ $b$;Runx2KO mice, while the level of Ptgs 2 mRNA was slightly lower in the ovary of $g c C b f b$;Runx2KO mice (Fig. 3A). Since Ptgs2 expresses in both granulosa and cumulus cells, we determined whether the expression of Ptgs 2 affected in the specific compartment in the follicle by in situ hybridization analyses (ISH). The localization of $\mathrm{Pgr}$ mRNA was also assessed to verify that this gene is up-regulated in individual preovulatory follicles comparable to wild-type animals. Indeed, Pgr mRNA was localized to granulosa cells of many preovulatory follicles in both wild-type and $g c C b f b ; R u n x 2 K O$ mice. Similarly, Ptgs 2 mRNA was localized to both granulosa and cumulus cells in both animal models, but there were no visible differences in the intensity and localization pattern in the ovary collected at $3 \mathrm{~h}$ after hCG administration (Fig. 3C). These data indicated that the double knockout mice were able to induce the expression of early key ovulatory genes in response to hCG stimulation similar to those observed in wild-type mice. This notion was further supported by our pilot study showing that Lhcgr mRNA was localized to granulosa and theca cells in the ovary of double KO mice collected before hCG administration (Supplementary Fig. 3A). Similarly, Cyp19a1 mRNA was also localized to granulosa cells (Supplementary Fig. 3B). Together, these data indicated that Lhcgr and Cyp19a1 were expressed in granulosa cells of follicles in the ovary of double $\mathrm{KO}$ mice during follicular development in a manner similar to those in wild-type mice.

In the previous study using $g c C b f b K O$ mice, we reported that the levels of mRNA for Edn2, Ptgs 1, Lhcgr, and $S f r p 4$ were lower in granulosa cells collected at $12 \mathrm{~h}$ post-hCG compared to those in wild-type animals ${ }^{10}$. In the current study, we also confirmed that the levels of mRNA for all these genes were significantly down-regulated in the ovary of double knockout mice at $11 \mathrm{~h}$ post-hCG (Fig. 3B). Because Ptgs 2 mRNA levels were reported to have a second peak at $12 \mathrm{~h}$ after hCG administration in mice ${ }^{31}$, we compared mRNA for this gene and found that the levels were significantly lower (Fig. 3B). Consistently, ptgs 2 mRNA was barely visible in double KO mouse ovaries at $11 \mathrm{~h}$ post-hCG, as demonstrated by In situ hybridization analysis (Fig. 3D). Taken together, these data suggested that double KO mice displayed marginal morphological and gene expression changes during the early ovulatory period while exhibiting more profound changes in gene expression during the late ovulatory period.

Thus far, we have identified three genes, Edn2, Ptgs1, and Ptgs2, that were directly linked to the ovulatory process and significantly down-regulated in $g c C b f b$; Run $x 2 \mathrm{KO}$ mice. To further identify ovulatory genes whose expression was affected in this anovulatory mutant mice, total RNA isolated from the ovaries collected at $11 \mathrm{~h}$ post-hCG was used for RNA-seq analyses ( $\mathrm{n}=4$ animals/ genotype). Differential gene expression analysis on 


\begin{tabular}{|c|c|}
\hline Official Gene Name & Fold change \\
\hline $\operatorname{Edn} 2$ (endothelin 2)* & -49.22 \\
\hline Cldn18 (claudin 18) & -16.89 \\
\hline Sfrp4 (secreted frizzled-related protein 4$)^{*}$ & -15.12 \\
\hline $\begin{array}{l}\text { Wnt10b (wingless-type MMTV integration site } \\
\text { family, member 10B) }\end{array}$ & -14.37 \\
\hline Has1 (hyaluronan synthase 1) & -12.84 \\
\hline Il11 (interleukin 11) & -11.89 \\
\hline Il6 (interleukin 6) & -11.86 \\
\hline $\begin{array}{l}\text { Serpine1 (serine (or cysteine) peptidase inhibitor, } \\
\text { clade E, member 1) }\end{array}$ & -9.82 \\
\hline Akr1c18 (aldo-keto reductase family 1, member C18) & -9.37 \\
\hline $\begin{array}{l}\text { Xpnpep2 (X-prolyl aminopeptidase (aminopeptidase } \\
\text { P) 2, membrane-bound) }\end{array}$ & -8.67 \\
\hline Spp1 (secreted phosphoprotein 1) & -8.23 \\
\hline Rtl1 (retrotransposon Gaglike 1) & -8.04 \\
\hline $\boldsymbol{K} \boldsymbol{l}$ (klotho) & -7.70 \\
\hline Rnf125 (ring finger protein 125) & -7.59 \\
\hline $\begin{array}{l}\text { Cemip (cell migration inducing protein, hyaluronan } \\
\text { binding)* }\end{array}$ & -7.22 \\
\hline Mmel1 (membrane metallo-endopeptidase-like 1)* & -7.12 \\
\hline $\begin{array}{l}\operatorname{Lrp8} \text { (low density lipoprotein receptor-related } \\
\text { protein 8, apolipoprotein e receptor)* }\end{array}$ & -6.61 \\
\hline Fosb (FBJ osteosarcoma oncogene B) & -6.31 \\
\hline $\begin{array}{l}\text { Prkg2 (protein kinase, cGMP-dependent, type II } \\
\text { (PGR downstream) }\end{array}$ & -6.29 \\
\hline Ankrd1 (ankyrin repeat domain 1 (cardiac muscle)) & -6.27 \\
\hline Ptgfr (prostaglandin F receptor)* & -6.09 \\
\hline Btg2 (B cell translocation gene 2, anti-proliferative) & -5.72 \\
\hline Ptgs2 (prostaglandin-endoperoxide synthase 2) & -5.66 \\
\hline Fosl1 (fos-like antigen 1) & -5.50 \\
\hline F3 (coagulation factor III) & -5.40 \\
\hline Fabp4 (fatty acid binding protein 4 , adipocyte) & -4.92 \\
\hline$A p \ln ($ apelin)* & -4.86 \\
\hline$H \boldsymbol{p}$ (haptoglobin)* & -4.83 \\
\hline Ptgs1 (prostaglandin-endoperoxide synthase 1)* & -4.74 \\
\hline $\begin{array}{l}\text { Adamts1 (a disintegrin-like and metallopeptidase } \\
\text { with thrombospondin type } 1 \text { motif, } 1 \text { ) }\end{array}$ & -4.34 \\
\hline $\begin{array}{l}\text { Lhcgr (luteinizing hormone/choriogonadotropin } \\
\text { receptor)* }\end{array}$ & -3.64 \\
\hline Sgkl (serum/glucocorticoid regulated kinase 1)* & -3.31 \\
\hline $\begin{array}{l}\text { Parm1 (prostate androgen-regulated mucin-like } \\
\text { protein 1) }\end{array}$ & -3.24 \\
\hline Junb (jun B proto-oncogene) & -2.99 \\
\hline Ctsl (cathepsin L) & -2.88 \\
\hline $\begin{array}{l}\text { Adamts } 4 \text { (a disintegrin-like and metallopeptidase } \\
\text { with thrombospondin type } 1 \text { motif, } 4 \text { ) }\end{array}$ & -2.78 \\
\hline Fos (FBJ osteosarcoma oncogene) & -2.47 \\
\hline Ccrl2 (chemokine (C-C motif) receptor-like 2)* & -2.47 \\
\hline Timp1 (tissue inhibitor of metalloproteinase 1)* & -2.39 \\
\hline $\begin{array}{l}\text { Adamts5 (a disintegrin-like and metallopeptidase } \\
\text { with thrombospondin type } 1 \text { motif, } 5 \text { ) }\end{array}$ & -2.10 \\
\hline
\end{tabular}

Table 1. A list of selected down-regulated genes in $g c R u n x 2$; $C b f b K O$ mice.

RNA-seq data revealed 715 and 293 genes as being down- and up-regulated in mutant mice compared to control mice, respectively $(q<0.05)$. The genes meeting the further criteria of the fold change of 2 or higher and average expression value of 0.5 or higher are listed in Supplementary Table 2 ( 342 genes met these criteria). These criteria were chosen to identify genes with both high expression levels and dramatic changes. Some of the most highly down- or up-regulated genes and the genes that are known to be involved in ovulation are listed in Tables 1 and 2. Included in these RNA-seq data and verified by qPCR are the genes that were previously found to be differentially regulated in cultured granulosa cells of Cbfb flox/flox $\mathrm{x} C y p 19^{\text {cre }}$ mice, including Edn2, Ptgs1, Sfrp4, and Lhcgr (marked with * in Tables 1 and 2 and Supplementary Table 2). 


\begin{tabular}{|l|l|}
\hline Official Gene Name & Fold change \\
\hline Hsd17b1 (hydroxysteroid (17-beta) dehydrogenase 1)* & 2.72 \\
\hline Vcam1 (vascular cell adhesion molecule 1) & 2.91 \\
\hline Inhbb (inhibin beta-B)* & 4.30 \\
\hline Grem1 (gremlin 1, DAN family BMP antagonist)* & 4.46 \\
\hline Cyp17a1 (cytochrome P450, family 17, subfamily a, polypeptide 1) & 6.16 \\
\hline Gpr83 (G protein-coupled receptor 83) & 9.71 \\
\hline
\end{tabular}

Table 2. A list of selected up-regulated genes in $g c R u n x 2 ; C b f b K O$ mice. ${ }^{*}$, genes which were previously identified to be differentially regulated in cultured granulosa cells isolated from $C b f b^{\text {flox/flox}}$; Cyp $19^{\text {cre }}$ mice compared to those from wild-type mice 9 . Fold changes were calculated by comparing the average values for mutant mouse samples vs. littermate control mouse samples ( $g c R u n x 2 ; C b f b K O / W i l d-t y p e)$. Lower expression in mutant mouse samples is given as -2 rather than 0.5 . The genes verified by qPCR were highlighted in green and red in Table 1 and Table 2, respectively.

Because many genes identified in RNA-seq analysis have not previously reported being expressed in the ovary and/or regulated by CBFs, we have also selected a group of genes that were highly affected in the ovary of $g c C b$ $f b ; R u n \times 2 K O$ mice for qPCR verification (Fig. $4 \mathrm{~A}$ ). Notable among the most highly down-regulated genes were Cldn18, Has1, Il11, and Il6 (Fig. 4A). CLDN18 is a tight junction molecule ${ }^{32,33}$. However, the ovarian expression of this protein is not known. The immunopositive staining for CLDN18 was localized to a few small patches of the granulosa cell compartment in periovulatory follicles at $11 \mathrm{~h}$ post-hCG, yet it was abundant in newly forming CLs in wild-type mouse ovaries (Fig. $4 \mathrm{~B}-\mathrm{a} \& \mathrm{~b}$ ). No staining was observed at $0 \mathrm{~h}$ post-hCG (data not shown). In wild-type adult mice, CLDN18 was localized to all CLs (Fig. 4B-c). In contrast, little staining for CLDN18 was detected in preovulatory and unruptured follicles of the double KO mice (Fig. 4B-d,e,f). HAS1 is an enzyme that synthesizes hyaluronic acid ${ }^{34}$. In situ hybridization analyses showed that Has $1 \mathrm{mRNA}$ was localized to cells in the theca layer and granulosa cells of preovulatory follicles in wild-type mouse ovaries, and this expression was diminished in the ovary of the mutant mice (Fig. 4C-a,d). Similarly, Il6 mRNA and Il11 mRNA were localized to the granulosa cell layer of preovulatory follicles and the theca layer, albeit with different intensity (Fig. 4C-b,c). As expected, the expression of these genes was down-regulated in the double $\mathrm{KO}$ mouse ovary.

In addition, the list of differentially regulated genes included clusters of genes involved in tissue remodeling (e.g., Serpine1, Mmel1, Adamts1, Cts1, Adamts4, Adamts5, and Timp1) and steroid metabolism (e.g., Ark1c18, Parm1, $H s d 17 b 11, H s d 3 b 6, H s d 17 b 1$, and Cyp17a1). Using qPCR analyses, we verified the downregulated expression of Serpine1, Adamts1, Adamts4, Adamts5, and Timp1 between and control mouse ovaries (Fig. 5A). In situ hybridization further demonstrated the localization of Serpine1 and Adamts1 mRNA in preovulatory follicles and newly forming CL in control animals and the down-regulated expression of these genes in the ovary of $g c C b f b ; R u n x 2 K O$ mice (Fig. 5B,C). qPCR analyses of genes involved in progesterone synthesis and metabolism showed that the levels of mRNA for Ark1c18, Parm1, Star, and Cyp11 were lower, whereas the levels of mRNA for Hsd17b1 and Cyp17a1 were higher in $g c C b f b$;Runx $2 \mathrm{KO}$ mouse ovaries than those in wild-type mouse ovaries (Fig. 5D). Similarly, serum progesterone levels were modestly decreased in double KO mice, but not statistically significant $(p=0.056)$, whereas estradiol levels were not different between wild-type and mutant mice at $11 \mathrm{~h}$ post-hCG (Fig. 5E).

gcCbfb;Runx2KO mice failed to develop normal CL. $g c C b f b ; R u n x 2 K O$ mice developed large preovulatory follicles but failed to ovulate in response to hCG or the LH surge. To determine whether these follicles develop into the CL, we examined ovaries collected at 24,48 , and $72 \mathrm{~h}$ after hCG administration. At $24 \mathrm{~h}$, ovaries of wild-type animals showed many forming CLs (Fig. 6A-a), while the ovary of double KO mice exhibited multiple large antral follicles, each with expanded COCs (Fig. 6A-b). To mark the CL and preovulatory follicles, ovarian sections were immunostained with HSD3B, an enzyme that catalyzes pregnenolone to progesterone (Fig. 6B). In wild-type animals, ovarian sections from post-ovulation time points showed typical CL development. In contrast, ovarian sections of $g c C b f b$; Runx $2 K O$ mice showed multiple unruptured follicles even at $48 \mathrm{~h}$ post-hCG. By Day $72 \mathrm{~h}$, no longer were these follicles present, but remained only small luteinized structures (Fig. 6B-f, wavy arrows). Consistent with these data, serum progesterone levels were completely diminished by $48 \mathrm{~h}$ post-hCG (Fig. 6C).

To investigate why periovulatory follicles failed to develop into the CL, we examined the expression of mRNA for Lhgcr and Prlr, two genes that are known to be essential for luteal development. The abundant expression for both Lhcgr and Prlr mRNA was localized to CLs at all three post-ovulatory time points in wild-type animals (Fig. 7A,B, upper panels), but little to no expression was detected in unruptured follicles and unruptured-then-collapsed poorly luteinized structures in the double KO mice (Fig. 7A,B, lower panels). These unruptured follicles also showed limited staining for PECAM-1, an endothelial cell marker (Fig. 8A, lower panel), indicating the defective angiogenesis/vascularization during CL formation and development. These unruptured-then-collapsed follicles in $g c C b f b$;Runx2KO mouse ovaries were riddled with apoptotic cells as demonstrated by extensive TUNEL staining at 48 and $72 \mathrm{~h}$ post-hCG (Fig. $8 \mathrm{~B}-\mathrm{e}, \mathrm{f})$.

\section{Discussion}

The present study is the first report showing that $g c C b f b$;Runx $2 \mathrm{KO}$ mice displayed profound defects in both ovulation and CL development. The majority of the double knockout mice failed to ovulate (>95\%) and develop functional CL, thus resulting in infertility. This anovulatory phenotype is likely the result of defects in the expression of specific genes, mainly in late ovulatory follicles. This notion is based on the findings that differences in the 
A)

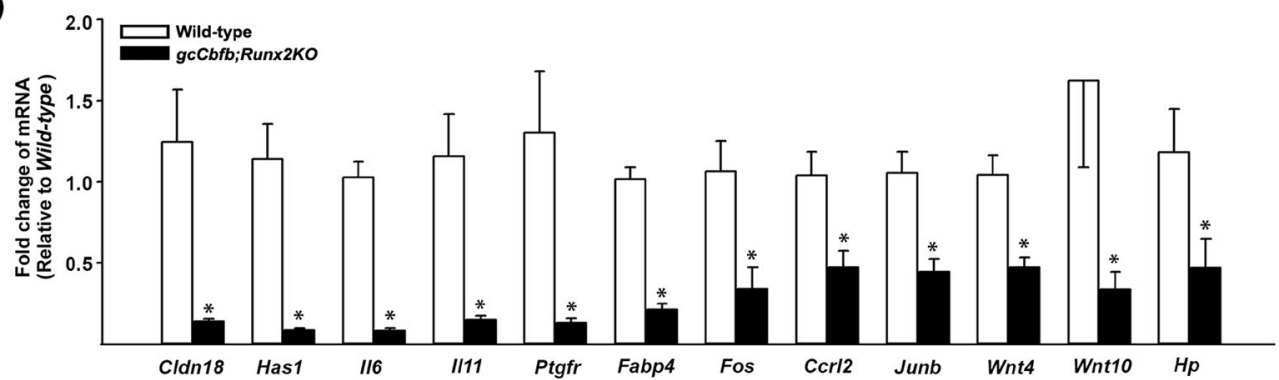

B) CLDN18
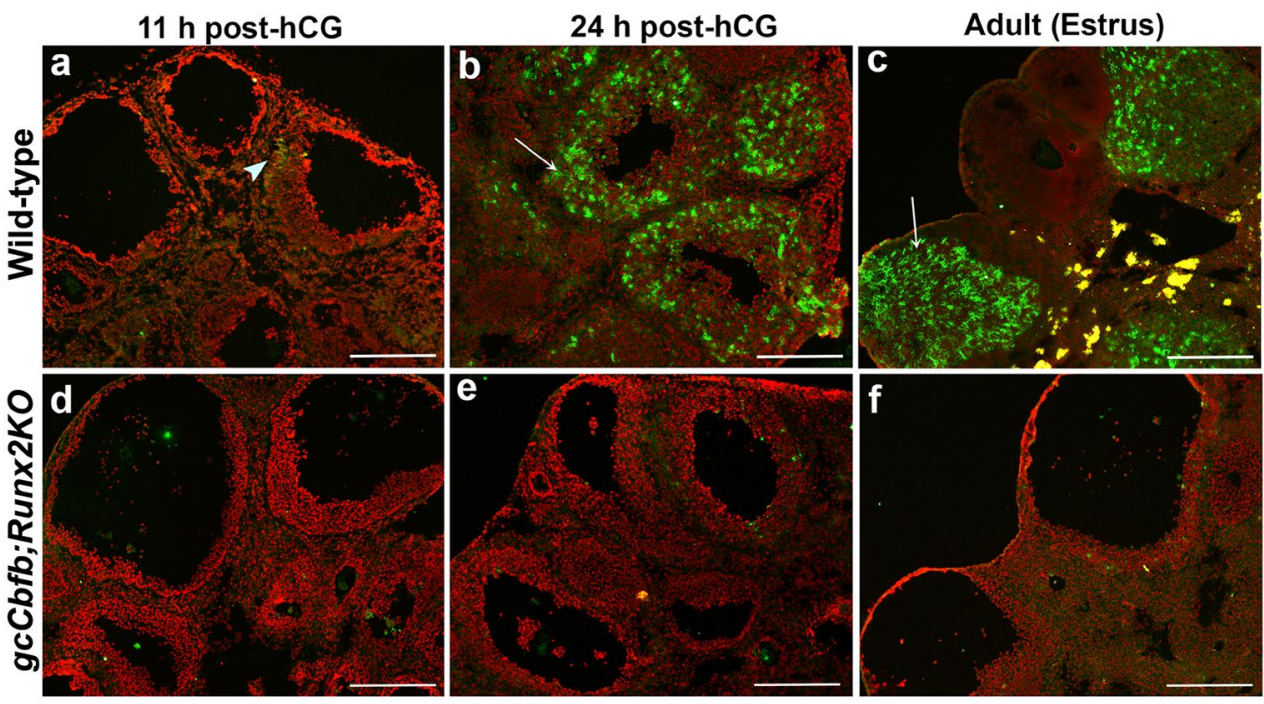

C)

Has1 mRNA

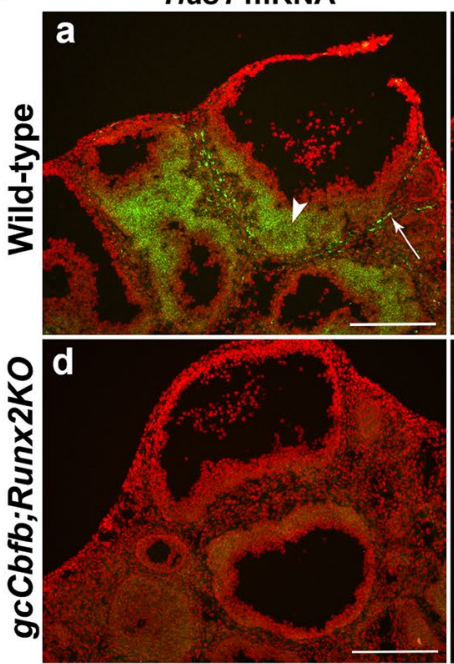

II6 mRNA
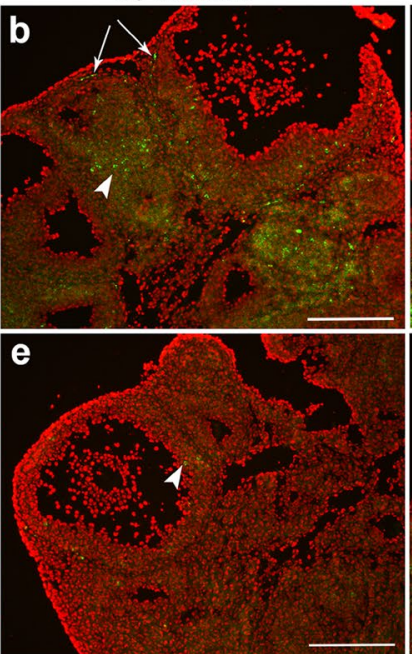

II1 mRNA
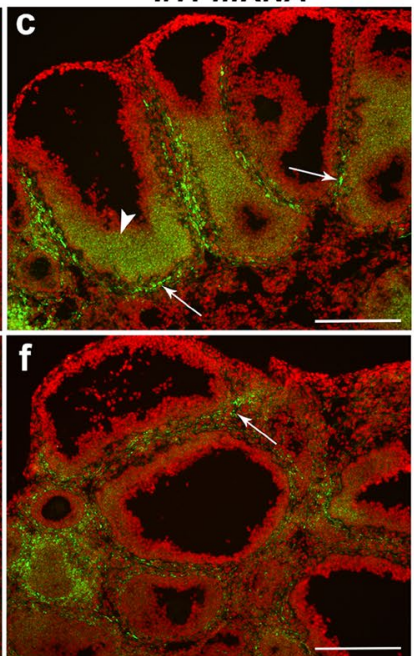

Figure 4. Identification of down-regulated genes in ovaries of $g c C b f b$;Runx $2 \mathrm{KO}$ mice (I). (A) Ovaries were collected at $11 \mathrm{~h}$ after hCG administration from wild-type and $g c C b f b ; R u n x 2 K O$ mice. A list of the most highly downregulated genes was selected from RNA-seq data analyses. The levels of mRNA for genes were measured by qPCR, normalizing to the Rpl19 value in each sample ( $\mathrm{n}=8$ and 7 for control and mutant mice, respectively). $* p<0.01$. (B) Ovaries were collected at 11 and $24 \mathrm{~h}$ after hCG administration from immature animals as well as in the morning of estrus from adult mice. The localization of CLDN18 was evaluated via immunohistochemical analyses ( $\mathrm{n}=3$ /genotype). CLDN18 was detected as green fluorescent staining, and the tissue sections were counterstained with propidium iodide (red). Arrowheads and arrows point to a few granulosa cells and luteal cells stained positively for CLDN18, respectively. (C) in situ hybridization analyses were used to localize mRNA for Has1, IL6, and IL11 in ovaries collected at $11 \mathrm{~h}$ post-hCG $(\mathrm{n}=3 /$ genotype). Transcripts for these genes were detected as green fluorescence signals. The tissue sections were counterstained with propidium iodide (red). Arrowheads and arrows point to granulosa cells of preovulatory follicles and cells in the theca layer positive for these gene transcripts, respectively. Scale bars, $250 \mu \mathrm{m}$ for all the images. 


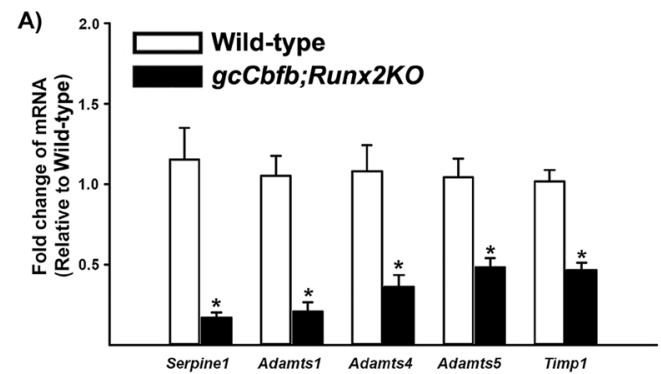

B) Serpine1 mRNA

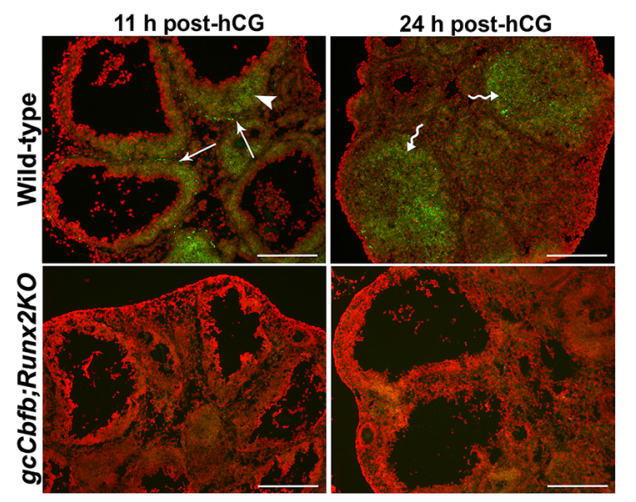

C) Adamts1 mRNA

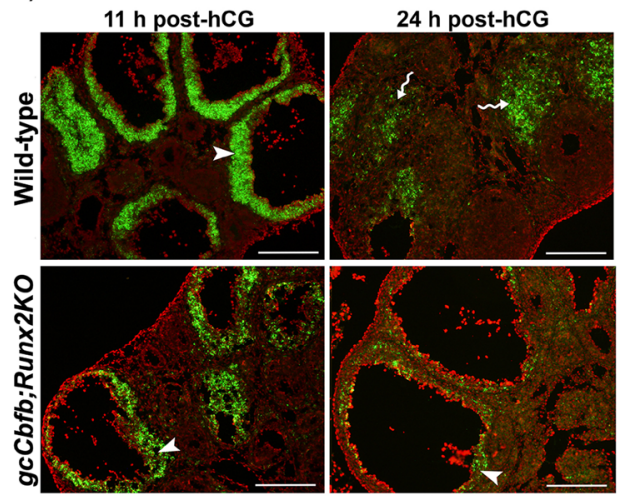

D)
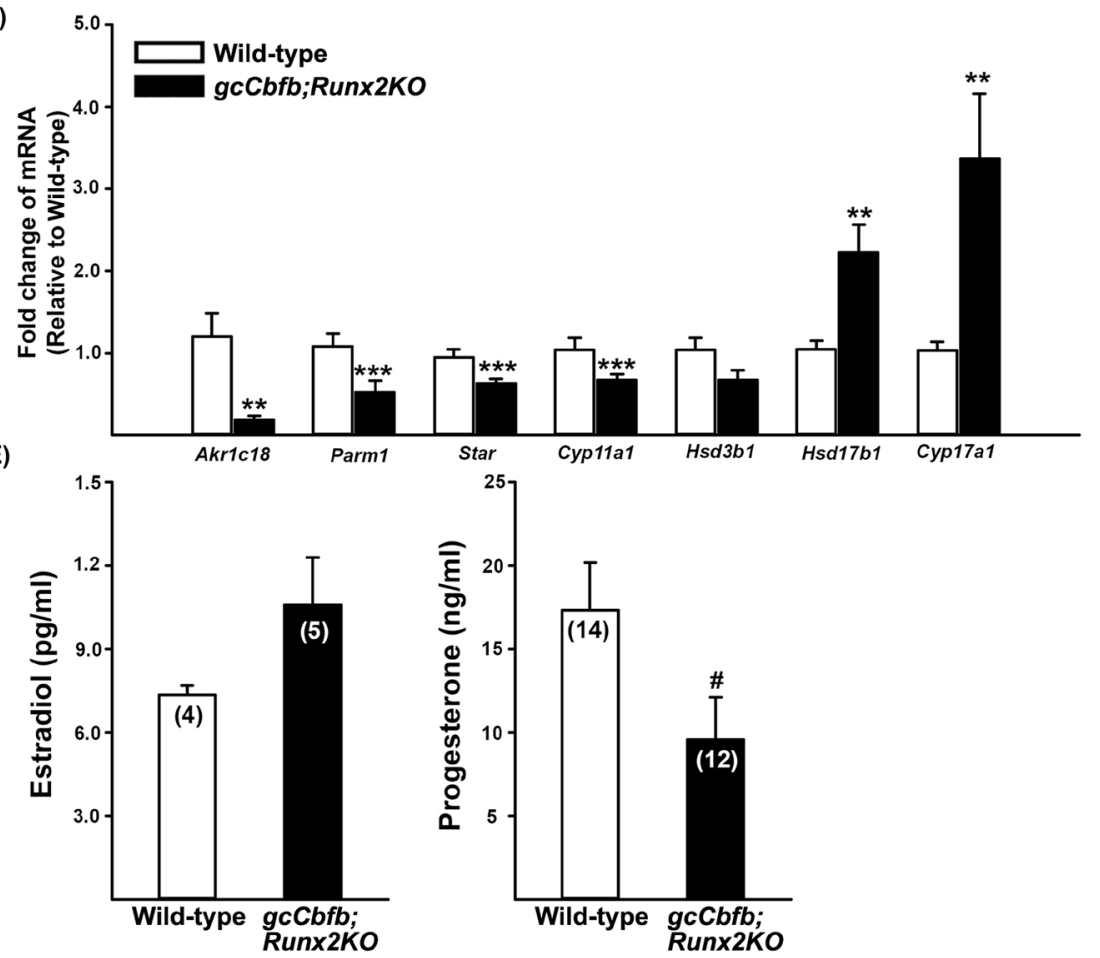

Figure 5. Identification of down-regulated genes in ovaries of $g c C b f b ; R u n x 2 K O$ mice (II). Ovaries were collected at $11 \mathrm{~h}$ after hCG administration from wild-type and $g c C b f b ; R u n x 2 K O$ mice. (A) The levels of mRNA for a cluster of genes associated with tissue remodeling were measured by qPCR, normalizing to the Rpl19 value in each sample ( $\mathrm{n}=8$ and 7 for control and mutant mice, respectively). $* p<0.005$. (B \& C) The localization of mRNA for Serpine1 and Adamts1 was detected via in situ hybridization analyses in ovaries collected at 11 and $24 \mathrm{~h}$ post-hCG $(\mathrm{n}=3$ /genotype). Transcripts for these genes were detected as green fluorescence signals. The tissue sections were counterstained with propidium iodide (red). Arrowheads, arrows, and wavy arrows point to granulosa cells of preovulatory follicles, cells in the theca layer, and luteal cells in the corpus luteum stained positive for these gene transcripts, respectively. Scale bars, $250 \mu \mathrm{m}$ for all the images. (D) The levels of mRNA for genes known to be involved in steroid metabolism were measured by qPCR, normalizing to the Rpl19 value in each sample ( $\mathrm{n}=8$ and 7 for control and mutant mice, respectively. $* * p<0.01$. $* * * p<0.05$. E) The levels of serum estradiol and progesterone were measured in blood samples collected at $11 \mathrm{~h}$ after hCG administration. The number inside each bar represents the sample size of mice evaluated. ${ }^{*} p=0.056$. 
A)

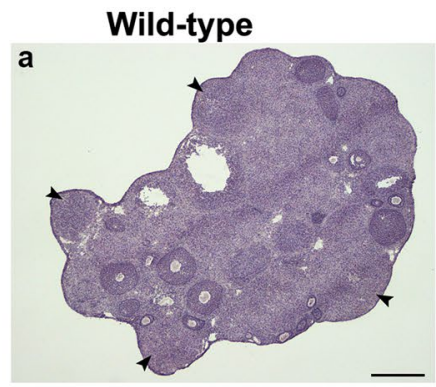

B)
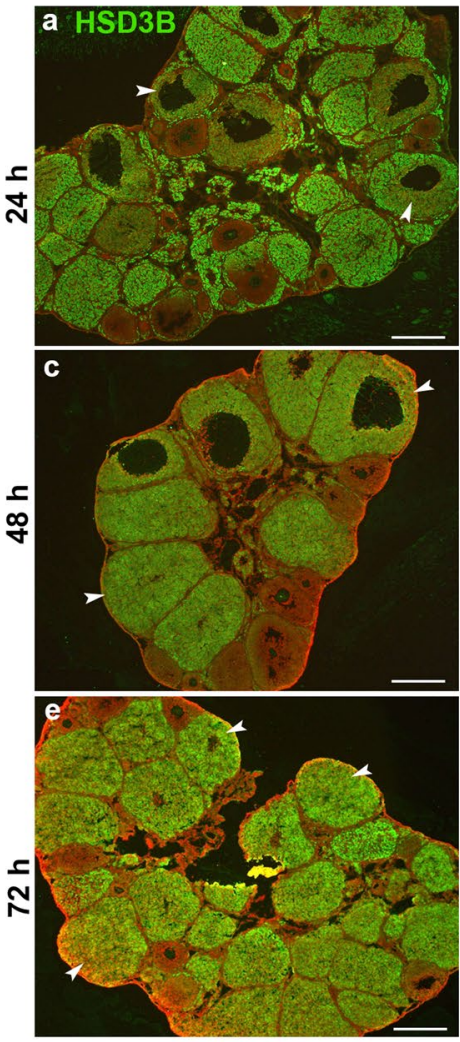

b

gcCbfb;Runx2KO

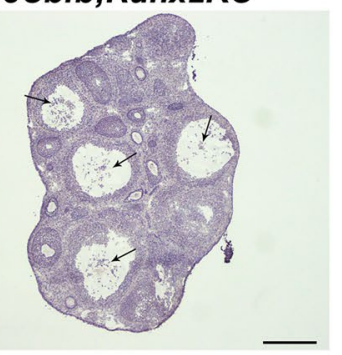

b

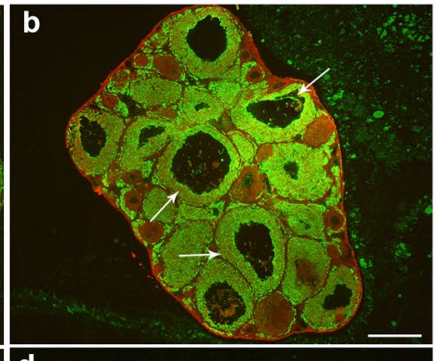

d
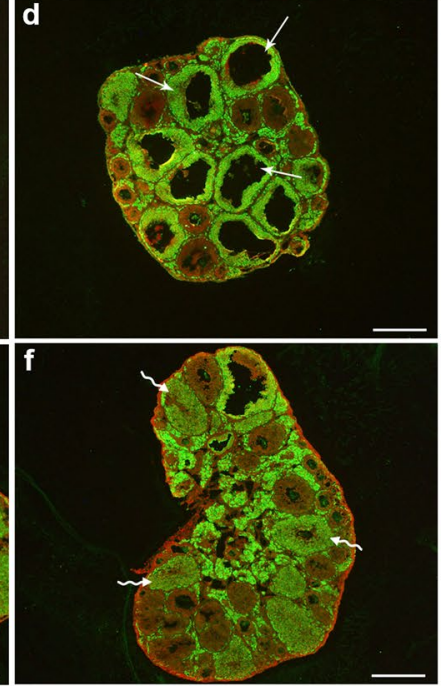

C)

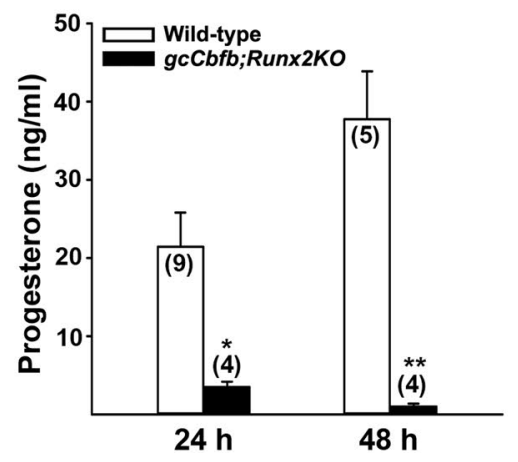

Figure 6. Assessment of ovarian morphology during the post-ovulatory period in $g c C b f b$;Runx $2 \mathrm{KO}$ mice. (A) Ovarian sections obtained at $24 \mathrm{~h}$ post-hCG were stained with hematoxylin ( $\mathrm{n}=3$ animals/ genotype). (B) Ovarian sections obtained at 24, 48, and $72 \mathrm{~h}$ post-hCG were immunostained for HSD3B to easily locate corpora lutea and unruptured follicles ( $\mathrm{n}=3$ animals/genotype). HSD3B was detected as green fluorescent staining, and ovarian sections were counterstained with propidium iodide (red). Arrowheads, arrows, and wavy arrows point to corpora lutea, unruptured follicles, and collapsed luteinized follicles, respectively. Scale bars, $500 \mu \mathrm{m}$ for all the images. (C) The levels of serum progesterone were measured in blood samples collected at 24 and $48 \mathrm{~h}$ after hCG administration. The number inside each bar represents the number of mice evaluated. $* p=0.024, * * p=0.001$. 


\section{A) Lhcgr mRNA}
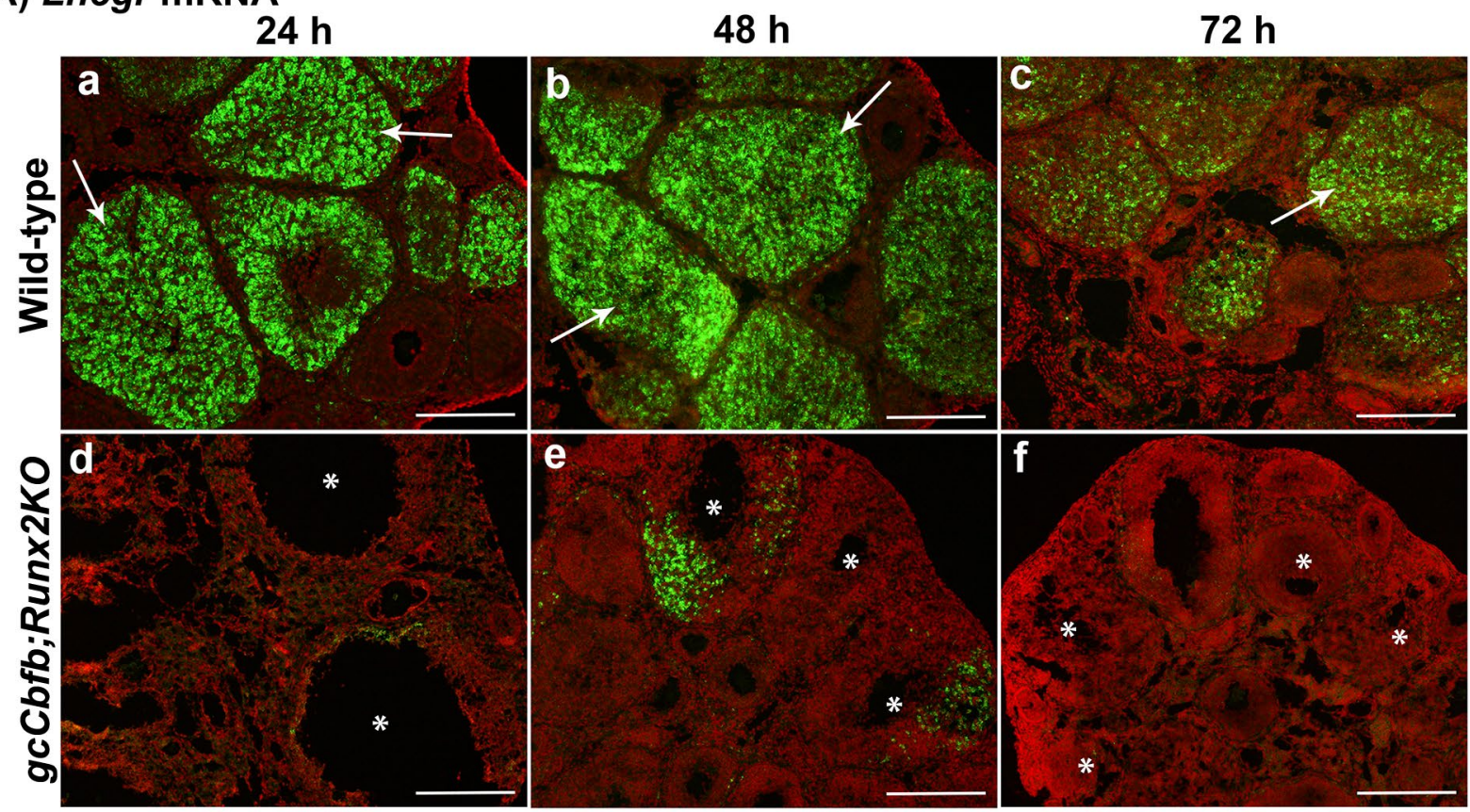

\section{B) PrIr mRNA}

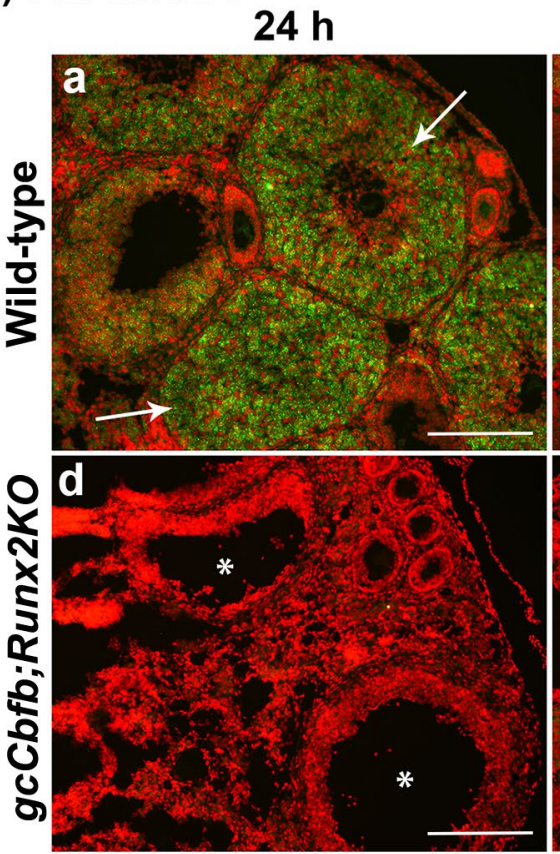

$48 \mathrm{~h}$
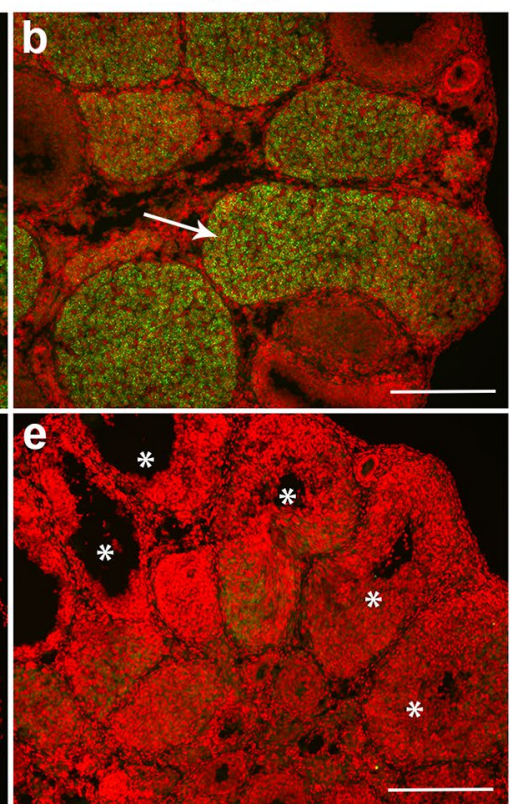

$72 \mathrm{~h}$

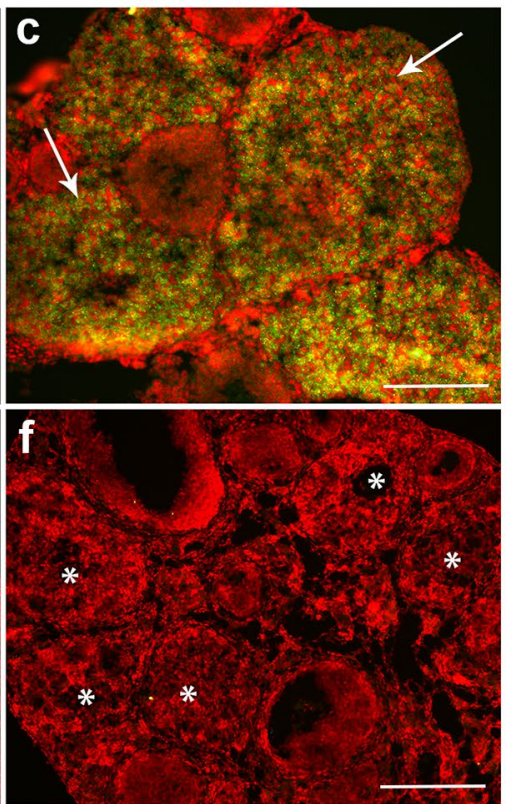

Figure 7. Assessment of the expression of Lhcgr and Prlr mRNA during the post-ovulatory period in $g c C b f b ; R u n x 2 K O$ mice. Ovaries collected at 24, 48, and $72 \mathrm{~h}$ after hCG administration were used to examine the expression of mRNA for $\operatorname{Lhcgr}(\mathbf{A})$ and $\operatorname{Prl}(\mathbf{B})$ by in situ hybridization analyses ( $\mathrm{n}=3$ animals/genotype). Transcripts for each gene were detected as green fluorescence signals. The ovarian sections were counterstained with propidium iodide (red). Arrows point to the CL expressing Lhcgr and Prlr mRNA in control animals, and the symbol (*) was placed in unruptured follicles and poorly luteinized collapsed follicles in $g c C b f b ; R u n x 2 \mathrm{KO}$ mice. Scale bars, $250 \mu \mathrm{m}$ for all the images.

expression of key ovulatory genes were observed at $11 \mathrm{~h}$ post-hCG (e.g., Edn2, Ptgs1, Ptgs2), but not in the early ovulatory period (eg., Areg, Ereg, Pgr). In support of this, the morphology of preovulatory follicles appears to be indistinguishable between control and mutant mice at both 3 and $11 \mathrm{~h}$ after hCG administration. Only after the expected time of ovulation was the histological difference apparent. In wild-type animals, ovaries contained many 


\section{A) PECAM-1}
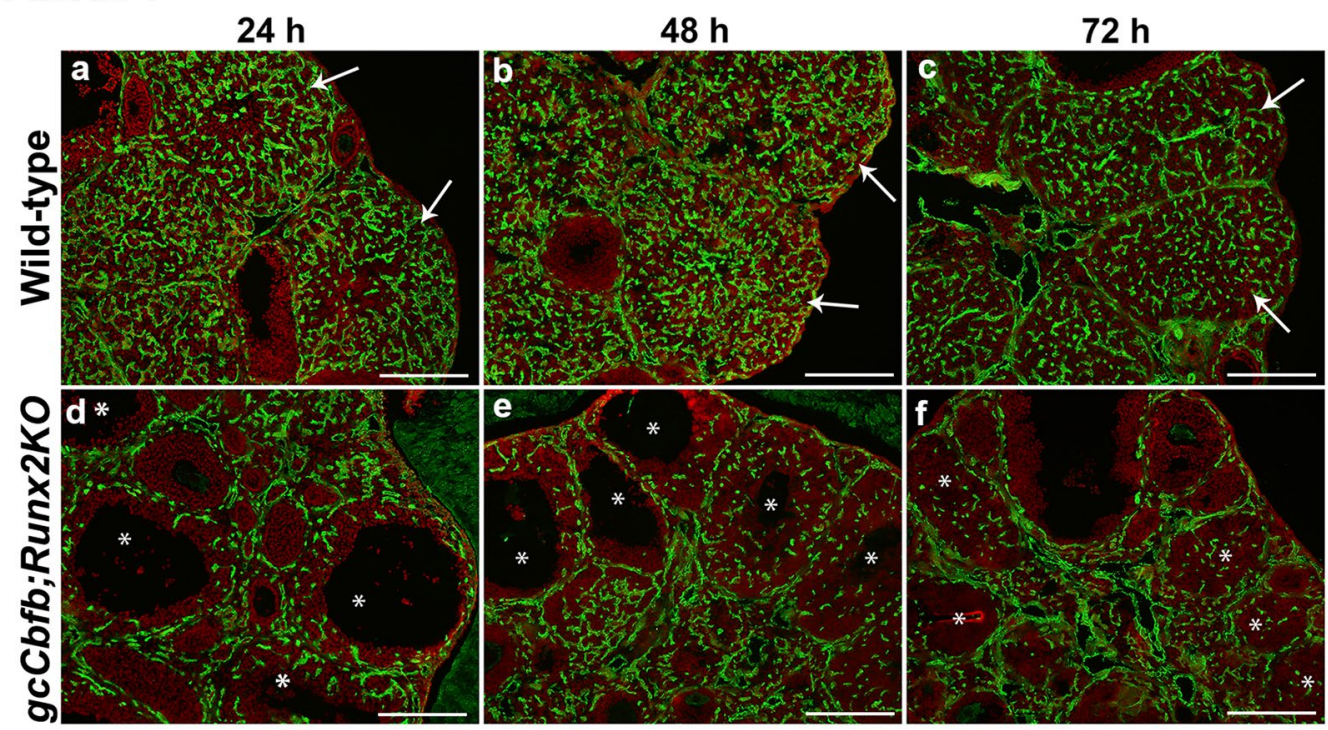

\section{B) TUNEL}

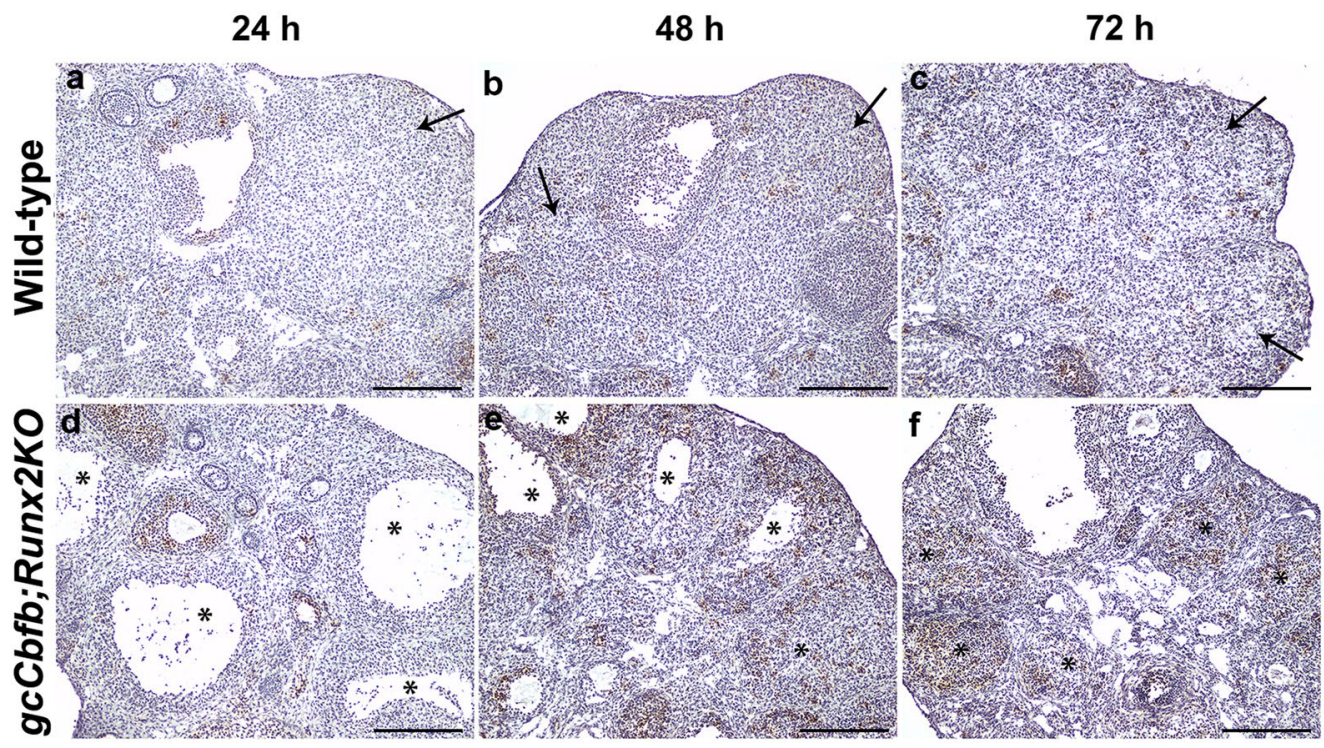

Figure 8. Assessment of vascularization and apoptosis during the post-ovulatory period in $g c C b f b ; R u n x 2 K O$ mice. Ovaries were collected at 24,48 , and $72 \mathrm{~h}$ after hCG administration $(\mathrm{n}=3$ animals/ genotype). (A) Immunohistochemical analysis was used to detect PECAM-1 (green fluorescence staining). The ovarian sections were counterstained with propidium iodide (red). (B) TUNEL assay was used to detect apoptotic cells (brown staining). The ovarian sections were counterstained with hematoxylin (blue). Arrows point to CLs in control animals and the symbol (*) was placed in unruptured follicles and poorly luteinized collapsed follicles in $g c C b f b ; R u n x 2 K O$ mice. Scale bars, $250 \mu \mathrm{m}$ for all the images.

newly forming CLs, whereas ovaries of the double $\mathrm{KO}$ mice showed multiple large antral follicles with entrapped expanding COCs, but no CLs.

The RNA-seq data analysis unveiled many genes whose expression was affected in the ovary of double KO mice during the periovulatory period. Notably, among the highly down-regulated genes are Cldn18, Has 1, and Il11, whose expression has not been documented in the mouse ovary. CLDN18 is a tight junction protein that regulates paracellular permeability and architectural integrity in various epithelial cells ${ }^{32,33}$. The present study documented that hCG increased the expression of Cldn18 in the mouse ovary, and the staining intensity of CLDN18 was highest in the forming CL. These data suggest that the primary role of CLDN18 is in CL formation, rather than the ovulatory process. HAS1 is an enzyme that synthesizes hyaluronan, a constituent of the extracellular matrix $^{34}$. In the ovary, the expression of Has2, another member of hyaluronic acid synthases, increases in cumulus cells of preovulatory follicles ${ }^{35}$, and this up-regulation is critical for cumulus expansion ${ }^{36}$. Herein, we documented that Has 1 mRNA expression also increased in preovulatory follicles after hCG administration in the mouse ovary. 
Together, these data indicated that both Has1 and Has2 expression increases in preovulatory follicles, and these proteins play an important role in the ovulatory process by providing an essential component of the extracellular matrix. The next highly down-regulated genes in our double knockout mice were Il11 and Il6, both of which are members of the IL6 type family of cytokines that share the common signal transducer receptor gp $130^{37}$ and exert overlapping functions ${ }^{38}$. Previously, Liu et al. ${ }^{39}$ showed that the levels of $I l 6 \mathrm{mRNA}$ were increased in both granulosa cells and COCs after hCG stimulation, and the treatment of IL6/its soluble receptor (IL-6SR) induced the expansion of mouse COCs, proposing that IL6 could act as a potent autocrine mediator involved in COC expansion. Jang et al. ${ }^{40}$ documented the localization of $I l 11$ mRNA predominantly in the thecal layer of the rat ovary after hCG administration. In addition, the treatment of IL11 increased progesterone production in cultured rat preovulatory follicles ${ }^{40}$. Our current data demonstrated the localization of mRNA for Il6 and Ill1 to granulosa and theca cells of preovulatory follicles and the compromised expression of these genes in the mutant mouse ovary. These data suggest that IL6 and IL11 are potential downstream targets of CBFs and are likely involved in the ovulatory process.

In addition to these genes, a cluster of genes involved in matrix remodeling was down-regulated in the double $\mathrm{KO}$ mouse ovary. Of these matrix remodeling genes, our particular interest was the down-regulated expression of Adamts1, Cts1, and Adamts4. These genes were reported to be down-regulated in Pgr knockout mice which failed to ovulate, but showed no visible defects in CL formation ${ }^{4,41}$, indicating that the reduced expression of these genes may contribute to the failure of follicle rupture in our mutant mice. Another group of genes differentially regulated were associated with steroid synthesis and metabolism. Interestingly, Akr1c18 and Parm1, two highly down-regulated genes, have an opposite function in progesterone metabolism; AKR1C18 metabolizes progesterone to an inactive form ${ }^{42-44}$, whereas PARM1 inhibits progesterone metabolism to an inactive form ${ }^{45}$, suggesting that the impact on progesterone metabolism by these two genes could be canceled out in the double KO mice. Along with these two genes, there was a minor reduction in Star and Cyp11a1 mRNA levels. In agreement with these findings, the progesterone levels were modestly decreased ( $p=0.056$, Fig. E) at $11 \mathrm{~h}$ after hCG administration. Meanwhile, the levels of mRNA for $H s d 17 b 1$ and $C y p 17 a 1$ were higher in the ovary of double mice. Since these genes are known to be involved in estradiol production ${ }^{46,47}$, we measured estradiol levels at both 3 and $11 \mathrm{~h}$ after hCG administration but found no difference between wild-type and mutant mice, suggesting that these changes were not sufficient to alter estradiol levels. It is also important to note that periovulatory progesterone levels were not altered in $g c C b f b K O$ mice $^{10}$, indicating that CBFs, likely through RUNX2, were involved in regulating the expression of selected genes associated with steroid metabolisms mentioned above. These changes also offered a glimpse into what would happen to periovulatory follicles after the expected time of ovulation in the double KO mouse ovary. In support of this notion, progesterone levels were further decreased at $24 \mathrm{~h}$ post-hCG and reached basal levels at $48 \mathrm{~h}$ post-hCG, consistent with the presence of poorly luteinized follicles at those time points.

The identification of these new genes differentially regulated in the double $\mathrm{KO}$ mice led to another question as to whether these genes mentioned above were uniquely regulated by RUNX2. We conducted preliminary studies comparing the expression of Ptgs2, Cldn18, and Adamts1 in the periovulatory ovary collected from 4 different mouse models (e.g., wild-type, $g c C b f b K O, g c R u n x 2 K O, g c C b f b ; R u n x 2 K O$ mice). In situ hybridization and Immunohistochemical data showed that the expression of all three genes was also reduced in $g c R u n x 2 K O$ mice compared to that in wild-type and $g c C b f b K O$ mice, although the most striking reduction was observed in the double KO mice (Supplementary Fig. 2). These data indicated that RUNX2 is likely a predominant regulator at least for these 3 genes in periovulatory follicles.

In addition to ovulatory defects, in $g c C b f b ; R u n x 2 K O$ mice, periovulatory follicles never really transformed into the CL. Even $48 \mathrm{~h}$ post-hCG, the unruptured follicles maintained an antrum, and by 72 after hCG administration, these unruptured follicles collapsed and showed a sign of excessive apoptosis, suggesting that they eventually would be removed from the ovary by the apoptotic process. These defects were also strongly correlated with the lack of vascularization in the unruptured follicles even far beyond the ovulation timing. Vascular development/angiogenesis is controlled by a complex network of factors, encompassing growth factors and cytokines, cell adhesion molecules, and extracellular matrix proteinases and their inhibitors. Bioinformatic analysis (DAVID Bioinformatics Resources 6.8) on a list of down-regulated genes from our RNA-seq data generated several gene clusters linked to vascular development and angiogenesis. These include cytokines (Il11, Il6, Clcf1, CXcl1, Ngf, Tnfsf15, F3), cell adhesion molecules (Cldn18, H2-Q10, Nacam, Pdcd1, Sele, Spn, Sdc1, Sdc4), and tissue remodeling proteinases and their inhibitors (Serpine1, Timp1, Adamts1, Adamts4, Adamts5, Mmel1, Pappa). Along with defects in vascular development, the failure to transform into the CL was correlated with the reduced expression of genes involved in luteinization. For instance, we verified the reduced levels for mRNA for Lhcgr, Ptgfr, Ccrl2, Sfrp4, Wnt4, and Wnt10 in the ovary of mutant mice even before ovulation occurs. Throughout the next 3 days after ovulation, the unruptured large antral follicles failed to acquire the expression of Lhcgr and Prlr, receptors for the two most critical luteotropic hormones ${ }^{48}$, thus resulting in a rapid demise of poorly luteinized follicles in mutant mice.

It is also important to note that many of genes identified as differentially expressed in the ovary of $g c C b f$ $b$; Runx2KO mice might not be direct transcriptional targets of RUNXs/CBFB, but rather their expressions were indirectly affected by the impact on the primary target of RUNXs/CBFB. Nevertheless, our RNA-seq data provide critical information that can be served as a foundation to identify the direct transcriptional target(s) of RUNXs/ CBFB in periovulatory follicles.

In summary, we found that in $g c C b f b ; R u n \times 2 K O$ mice, ovulation and CL formation were completely inhibited, indicating that both RUNX1 and RUNX2 with their common partner CBFB in the ovary are required for successful ovulation and CL development. In support of this notion, Runx2 deletion in granulosa cells ( $g c R u n x 2 \mathrm{KO}$ mice) resulted in a partial reduction in ovulation rates. Moreover, they appeared to have histologically normal-looking $\mathrm{CL}$, indicating that unruptured follicles eventually transformed into the CL. In addition, the current RNA-seq 
data revealed that CBFs affect the expression of a diverse set of genes in ovulatory follicles and newly forming CL. Included in the list of genes are several clusters of genes associated with inflammation, matrix remodeling, cell differentiation, vascularization, and steroid metabolism. From in vivo data generated from the present study and our previous study ${ }^{10}$, we propose that the overlapping expression of Runx1 and Runx2 in ovulatory follicles not only brings about effective synergism required for successful ovulation and subsequent luteinization but also serves a necessary compensatory mechanism to ensure the success of these two critical events in the ovary.

\section{Materials and Methods}

Animals. All animals were treated in accordance with the National Institutes of Health Guide for the Care and Use of Laboratory Animals. Animal protocols were approved by the University of Kentucky Animal Care and Use Committees. Cbfb flox17, Runx $2^{f l o x 49}$, and $E s r 2^{C r e 50}$ mutant mice were used to generate granulosa cell-specific deletion of $C b f b$ and Runx2. All mice were maintained on a $12 \mathrm{~h} \mathrm{light/dark} \mathrm{cycle} \mathrm{with} \mathrm{water} \mathrm{and} \mathrm{food} \mathrm{ad} \mathrm{libitum} \mathrm{at}$ the University of Kentucky Division of Laboratory Animal Resources. For the gonadotropin-induced ovulation model, mice (25 days old) were injected with pregnant mare serum gonadotropin (PMSG, 5 IU, i.p.), followed $48 \mathrm{~h}$ later with human chorionic gonadotropin (hCG, 5 IU, i.p.). In our colony, the mice ovulated approximately $12 \mathrm{~h}$ after hCG administration ${ }^{10}$. To determine the stage of the estrous cycle, the vaginal fluid containing cells were obtained from adult female mice ( $>3$ months old) daily for at least two cycles and examined microscopically.

Genotyping. To genotype mice, ear punches were used to isolate genomic DNA using the AccuStar II Mouse Genotyping Kit (Quantabio) according to the manufacturer's instructions. PCR was conducted with primers for Cbfb flox ${ }^{17}$, Run $x 2$ flox $^{48}$, and Esr2 Cre ${ }^{50}$ listed in Supplementary Table 1, and amplified PCR products were run on $2 \%$ agarose gel for examination.

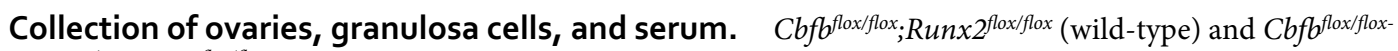
;Esr2 ${ }^{\text {cre/ }}$; Runx $2^{\text {flox/flox }}$ ( $g c C b f b$;Runx $2 \mathrm{KO}$ ) mice were collected at 3, 11, 16, 24, 48, or $72 \mathrm{~h}$ after hCG administration. Granulosa cells were isolated from ovaries collected at $11 \mathrm{~h}$ post-hCG via follicular puncture as described previously ${ }^{9}$. Serum samples were collected by cardiac puncture at the time of euthanization.

Quantitative analysis of mRNA levels and RNA sequencing (RNA-seq) analysis. Total RNA was isolated from ovaries using a Trizol reagent (Invitrogen) and from granulosa cells using an RNeasy mini kit (QIAGEN). Levels of mRNA for genes of interest were measured by qPCR according to the method described previously 9 . Oligonucleotide primers for all genes analyzed were designed using the PRIMER3 Program and listed in Supplementary Table 1. Official full names for the genes described in the manuscript are listed in Tables as well as Supplementary Tables.

For the RNA-seq analysis, total RNA isolated from ovaries were used for library construction and then for sequencing at the DNA Services division of the Roy J. Carver Biotechnology Center at the University of Illinois. Briefly, strand-specific RNAseq libraries for eight individual samples were prepared using a TruSeq Stranded RNA Sample Prep kit (Illumina). These samples represent $n=4$ independent samples per mouse line examined. The libraries were quantitated by qPCR and sequenced on one lane for 101 cycles from one end of the fragments on a NovaSeq. 6000 using a NovaSeq S2 reagent kit. Fastq files were generated and demultiplexed with the bcl2fastq v2.20 Conversion Software (https://support.illumina.com/downloads/bcl2fastq-conversion-software-v2-20. $\mathrm{html}$ ). Adaptor sequences were trimmed from the 3'-end of the reads. Average per-base read quality scores were over 30 in all samples, indicating that those reads were high in quality. RNA-seq data were analyzed at the High Performance Computing in Biology group at the University of Illinois. Briefly, the Mus Musculus transcriptome and Annotation Release 106 (GRCm38.p6) from NCBI were used for quasi-mapping and count generation using Salmon (version 0.11 .3 ) $^{51}$. Gene-level counts were then estimated based on transcript-level counts using the biased corrected counts without an offset method from the Tximport package ${ }^{52}$. For the statistical analysis, the numbers of reads per gene were normalized via performing TMM (trimmed mean of $M$ values) normalization in the edgeR package ${ }^{53}$ and expressed as normalized log2-based count per million values (logCPM) calculated using edgeR's cpm() function ${ }^{54}$. Differential gene expression analysis for wild-type vs. $g c C b f b ; R u n x 2 K O$ mice was performed using the limma-trend method on the logCPM values ${ }^{55,56}$. Multiple testing correction was done using the False Discovery Rate (FDR) method ${ }^{57}$. We defined the threshold for significant differential expression as FDR (q) value $<0.05$.

In Situ localization of mRNA for Pgr, Ptgs2, Has1, Il6, Il11, Serpine1, Adamts1, Lhcgr, and Prlr. Ovaries were collected from PMSG/hCG-primed immature mice at defined times after hCG injection or from adult mice on the day of estrus. Frozen ovaries were sectioned at $10 \mu \mathrm{m}$ and mounted on ProbeOn Plus slides (Fisher Scientific). In situ hybridization analysis was carried out as described previously ${ }^{9,10}$. Briefly, partial cDNA fragments were amplified using primers designed for mouse Pgr, Ptgs2, Has1, Il6, Il11, Serpine1, Adamts1, Lhcgr, and Prlr using total RNA samples isolated from ovaries at 3 or $11 \mathrm{~h}$ or 3 days post-hCG. The amplified PCR fragments were cloned into pCRII-TOPO Vector. Sequences of the cloned DNA were verified commercially (Eurofins Genomics). Plasmids containing partial cDNA for these genes were linearized using the appropriate restriction enzymes (e.g., EcoRV, HindIII, or BamHI). Sense and antisense riboprobes were synthesized using the corresponding linearized plasmids and labeled with Fluorescein-12-UTP. The ovarian sections hybridized with fluorescein-labeled probes were incubated with the anti-fluorescein antibody. Hybridized riboprobes were amplified using a TSA-plus fluorescein kit (Roche Applied Sciences). The sections were counterstained with propidium iodide. Specific signals were visualized with an Eclipse E800 Nikon microscope under fluorescent optics.

Immunohistochemical analyses and apoptosis detection. Frozen sections $(10 \mu \mathrm{m})$ were fixed using an appropriate medium (e.g., acetone, $4 \%$ paraformaldehyde, or $10 \%$ formalin solution) and incubated with 
primary antibodies for RUNX1 (D33G6, Cell Signaling,1:200 dilution), RUNX2 (D1L7F, Cell Signaling, 1:200 dilution), HSD3B (HPA009712, Santa Cruz Biotechnology, 1:500 dilution), CYP11A1 (D8F4F, Cell Signaling, 1:500 dilution), CLDN18 (34H14L15, Invitrogen, 1: 200 dilution), or CD31 (MEC 13.3, BD Biosciences, 1:5000 dilution) at $4{ }^{\circ} \mathrm{C}$ according to the manufacturer's instructions ${ }^{10}$. After rinsing with PBS, the sections were incubated with appropriate Alexa Fluor secondary antibodies (Life Technologies), counterstained with propidium iodide, and mounted with a mounting medium (fluorogel, DABCO). Digital images were captured using an Eclipse E800 Nikon microscope, with exposure time kept constant for sections incubated with the same primary antibody.

For detection of apoptotic cells, ovarian sections were subjected to TUNEL assay using the ApopTag in situ apoptosis detection kit according to the manufacturer's instructions (EMD Millipore).

Western blot analysis. The whole cell lysate was extracted from granulosa cells collected at $11 \mathrm{~h}$ post-hCG using a Nuclear Extraction Kit (Active Motif) according to the manufacturer's instructions. Cell lysates were denatured by boiling for $5 \mathrm{~min}$, separated using SDS-PAGE, and transferred onto a nitrocellulose membrane. Membranes were incubated with the primary antibody against RUNX2 (SC-10758, Santa Cruz) and CBFB (33516, Abcam) overnight at $4{ }^{\circ} \mathrm{C}^{20}$. Beta-actin (Cell Signaling Technology Inc.) was used as a loading control. Blots were incubated with the respective secondary horseradish peroxidase-conjugated antibody (Santa Cruz Biotechnology) for $1 \mathrm{~h}$. Peroxidase activity was visualized using the Amersham ECL Prime Western Blotting Detection Reagent (GE Healthcare).

Immunoassay of estradiol and progesterone. Concentrations of estradiol and progesterone in serum samples were measured by an estradiol rat/mouse ELISA kit (Calbiotech) and progesterone rat/mouse ELISA kit (IBL international), respectively. Assay sensitivity for estradiol and progesterone was $3 \mathrm{pg} / \mathrm{ml}$ and $0.4 \mathrm{ng} /$ $\mathrm{ml}$, respectively. The intra-assay coefficient of variation for estradiol and progesterone was $9.2 \%$ and $6.2 \%$, respectively.

Statistical analysis. All data are presented as mean \pm SEM. Statistical significance between mean values of wild-type and $g c C b f b$;Runx2KO samples was determined using an independent sample T-test in the SPSS statistics 23 . Values were considered significantly different if $p<0.05$.

\section{Data availability}

The datasets generated and analyzed as a part of this study are available in the NCBI Gene Expression Omnibus (GSE140922).

Received: 13 September 2019; Accepted: 12 March 2020;

Published online: 18 June 2020

\section{References}

1. Duffy, D. M., Ko, C., Jo, M., Brannstrom, M. \& Curry, T. E. Ovulation: Parallels With Inflammatory Processes. Endocrine Reviews 40, 369-416 (2019).

2. Richards, J. S., Russell, D. L., Ochsner, S. \& Espey, L. L. Ovulation: new dimensions and new regulators of the inflammatory-like response. Annual review of physiology 64, 69-92 (2002).

3. Bertolin, K., Gossen, J., Schoonjans, K. \& Murphy, B. D. The orphan nuclear receptor Nr5a2 is essential for luteinization in the female mouse ovary. Endocrinology 155, 1931-1943 (2014).

4. Robker, R. L. et al. Progesterone-regulated genes in the ovulation process: ADAMTS- 1 and cathepsin L proteases. Proceedings of National Academy of Sciences of the United States of America 97, 4689-4694 (2000).

5. Fan, H. Y., Liu, Z., Johnson, P. F. \& Richards, J. S. CCAAT/enhancer-binding proteins (C/EBP)-alpha and -beta are essential for ovulation, luteinization, and the expression of key target genes. Molecular endocrinology 25, 253-268 (2011).

6. Kim, J. et al. Peroxisome proliferator-activated receptor gamma is a target of progesterone regulation in the preovulatory follicles and controls ovulation in mice. Molecular and cellular biology 28, 1770-1782 (2008).

7. Tullet, J. M. et al. Multiple signaling defects in the absence of RIP140 impair both cumulus expansion and follicle rupture. Endocrinology 146, 4127-4137 (2005).

8. Hernandez-Gonzalez, I. et al. Gene expression profiles of cumulus cell oocyte complexes during ovulation reveal cumulus cells express neuronal and immune-related genes: does this expand their role in the ovulation process? Molecular endocrinology 20 , 1300-1321 (2006).

9. Wilson, K. et al. Core Binding Factor-beta Knockdown Alters Ovarian Gene Expression and Function in the Mouse. Molecular endocrinology 30, 733-747 (2016).

10. Lee-Thacker, S. et al. Core Binding Factor beta Expression in Ovarian Granulosa Cells Is Essential for Female Fertility. Endocrinology 159, 2094-2109 (2018).

11. Friedman, A. D. Cell cycle and developmental control of hematopoiesis by Runx1. Journal of cellular physiology 219, 520-524 (2009).

12. Wang, Q. et al. Disruption of the Cbfa2 gene causes necrosis and hemorrhaging in the central nervous system and blocks definitive hematopoiesis. Proceedings of National Academy of Sciences of the United States of America 93, 3444-3449 (1996).

13. Komori, T. et al. Targeted disruption of Cbfal results in a complete lack of bone formation owing to maturational arrest of osteoblasts. Cell 89, 755-764 (1997).

14. Li, Q. L. et al. Causal relationship between the loss of RUNX3 expression and gastric cancer. Cell 109, 113-124 (2002).

15. Inoue, K. et al. Runx3 controls the axonal projection of proprioceptive dorsal root ganglion neurons. Nature neuroscience 5, 946-954 (2002).

16. Wang, Q. et al. The CBFbeta subunit is essential for CBFalpha2 (AML1) function in vivo. Cell 87, 697-708 (1996).

17. Naoe, Y. et al. Repression of interleukin- 4 in T helper type 1 cells by Runx/Cbf beta binding to the Il4 silencer. The Journal of experimental medicine 204, 1749-1755 (2007).

18. Sasaki, K. et al. Absence of fetal liver hematopoiesis in mice deficient in transcriptional coactivator core binding factor beta. Proceedings of National Academy of Sciences of the United States of America 93, 12359-12363 (1996).

19. Jo, M. \& Curry, T. E. Jr. Luteinizing hormone-induced RUNX1 regulates the expression of genes in granulosa cells of rat periovulatory follicles. Molecular endocrinology 20, 2156-2172 (2006). 
20. Park, E. S. et al. RUNX2 transcription factor regulates gene expression in luteinizing granulosa cells of rat ovaries. Molecular endocrinology 24, 846-858 (2010).

21. Shimada, M., Hernandez-Gonzalez, I., Gonzalez-Robayna, I. \& Richards, J. S. Paracrine and autocrine regulation of epidermal growth factor-like factors in cumulus oocyte complexes and granulosa cells: key roles for prostaglandin synthase 2 and progesterone receptor. Molecular endocrinology 20, 1352-1365 (2006).

22. Morita, K. et al. Genetic regulation of the RUNX transcription factor family has antitumor effects. The Journal of clinical investigation 127, 2815-2828 (2017).

23. Kimura, A. et al. Runx1 and Runx2 cooperate during sternal morphogenesis. Development 137, 1159-1167 (2010).

24. Liu J, Park ES, Curry TE, Jr., Jo M. Periovulatory expression of hyaluronan and proteoglycan link protein 1 (Hapln1) in the rat ovary: hormonal regulation and potential function. Molecular endocrinology 24, 1203-1217 (2010).

25. Park, E. S., Park, J., Franceschi, R. T. \& Jo, M. The role for runt related transcription factor 2 (RUNX2) as a transcriptional repressor in luteinizing granulosa cells. Molecular and cellular endocrinology 362, 165-175 (2012).

26. Okuda, T., van Deursen, J., Hiebert, S. W., Grosveld, G. \& Downing, J. R. AML1, the target of multiple chromosomal translocations in human leukemia, is essential for normal fetal liver hematopoiesis. Cell 84, 321-330 (1996).

27. Cacioppo, J. A. et al. Generation of an estrogen receptor beta-iCre knock-in mouse. Genesis 54, 38-52 (2016).

28. Fan, H. Y. et al. Selective expression of KrasG12D in granulosa cells of the mouse ovary causes defects in follicle development and ovulation. Development 135, 2127-2137 (2008).

29. Park, J. Y. et al. EGF-like growth factors as mediators of LH action in the ovulatory follicle. Science 303, 682-684 (2004).

30. Davis, B. J. et al. Anovulation in cyclooxygenase-2-deficient mice is restored by prostaglandin E2 and interleukin-1beta. Endocrinology 140, 2685-2695 (1999).

31. Joyce, I. M., Pendola, F. L., O’Brien, M. \& Eppig, J. J. Regulation of prostaglandin-endoperoxide synthase 2 messenger ribonucleic acid expression in mouse granulosa cells during ovulation. Endocrinology 142, 3187-3197 (2001).

32. Niimi, T. et al. Claudin-18, a novel downstream target gene for the T/EBP/NKX2.1 homeodomain transcription factor, encodes lung- and stomach-specific isoforms through alternative splicing. Molecular and cellular biology 21, 7380-7390 (2001).

33. LaFemina, M. J. et al. Claudin-18 deficiency results in alveolar barrier dysfunction and impaired alveologenesis in mice. American journal of respiratory cell and molecular biology 51,550-558 (2014).

34. Itano, N. \& Kimata, K. Expression cloning and molecular characterization of HAS protein, a eukaryotic hyaluronan synthase. The Journal of biological chemistry 271, 9875-9878 (1996).

35. Ochsner, S. A., Russell, D. L., Day, A. J., Breyer, R. M. \& Richards, J. S. Decreased expression of tumor necrosis factor-alphastimulated gene 6 in cumulus cells of the cyclooxygenase-2 and EP2 null mice. Endocrinology 144, 1008-1019 (2003).

36. Chen, L., Russell, P. T. \& Larsen, W. J. Functional significance of cumulus expansion in the mouse: roles for the preovulatory synthesis of hyaluronic acid within the cumulus mass. Molecular reproduction and development 34, 87-93 (1993).

37. Barton, V. A., Hall, M. A., Hudson, K. R. \& Heath, J. K. Interleukin-11 signals through the formation of a hexameric receptor complex. The Journal of biological chemistry 275, 36197-36203 (2000)

38. Lokau, J., Agthe, M., Flynn, C. M. \& Garbers, C. Proteolytic control of Interleukin-11 and Interleukin-6 biology. Biochimica et biophysica acta. Molecular cell research 1864, 2105-2117 (2017).

39. Liu, Z. et al. IL6: an autocrine regulator of the mouse cumulus cell-oocyte complex expansion process. Endocrinology 150, 3360-3368 (2009).

40. Jang, Y. J. et al. Regulation of interleukin-11 expression in ovulatory follicles of the rat ovary. Reproduction, fertility, and development 29, 2437-2445 (2017)

41. Richards, J. S. et al. Regulated expression of ADAMTS family members in follicles and cumulus oocyte complexes: evidence for specific and redundant patterns during ovulation. Biology of reproduction 72, 1241-1255 (2005)

42. Piekorz, R. P., Gingras, S., Hoffmeyer, A., Ihle, J. N. \& Weinstein, Y. Regulation of progesterone levels during pregnancy and parturition by signal transducer and activator of transcription 5 and 20 alpha-hydroxysteroid dehydrogenase. Molecular endocrinology 19, 431-440 (2005).

43. Wiest, W. G. On the function of 20 alpha-hydroxypregn-4-en-3-one during parturition in the rat. Endocrinology 83, 1181-1184 (1968).

44. Mejia, R., Waite, C. \& Ascoli, M. Activation of Gq/11 in the mouse corpus luteum is required for parturition. Molecular endocrinology 29, 238-246 (2015)

45. Park, J. Y., Jang, H., Curry, T. E., Sakamoto, A. \& Jo, M. Prostate androgen-regulated mucin-like protein 1: a novel regulator of progesterone metabolism. Molecular endocrinology 27, 1871-1886 (2013).

46. Akinola, L. A., Poutanen, M., Vihko, R. \& Vihko, P. Expression of 17beta-hydroxysteroid dehydrogenase type 1 and type 2, P450 aromatase, and 20 alpha-hydroxysteroid dehydrogenase enzymes in immature, mature, and pregnant rats. Endocrinology 138, 2886-2892 (1997).

47. Luu-The, V. Analysis and characteristics of multiple types of human 17beta-hydroxysteroid dehydrogenase. The Journal of steroid biochemistry and molecular biology 76, 143-151 (2001).

48. Stocco, C., Telleria, C. \& Gibori, G. The molecular control of corpus luteum formation, function, and regression. Endocrine review 28, 117-149 (2007).

49. Takarada, T. et al. An analysis of skeletal development in osteoblast-specific and chondrocyte-specific runt-related transcription factor-2 (Runx2) knockout mice. Journal of bone and mineral research: the official journal of the American Society for Bone and Mineral Research 28, 2064-2069 (2013).

50. Cacioppo, J. A. et al. Granulosa cell endothelin-2 expression is fundamental for ovulatory follicle rupture. Scientific reports 7, 817 (2017).

51. Patro, R., Duggal, G., Love, M. I., Irizarry, R. A. \& Kingsford, C. Salmon provides fast and bias-aware quantification of transcript expression. Nature methods 14, 417-419 (2017).

52. Soneson, C., Love, M. I. \& Robinson, M. D. Differential analyses for RNA-seq: transcript-level estimates improve gene-level inferences. F1000Research 4, 1521 (2015).

53. Robinson, M. D. \& Oshlack, A. A scaling normalization method for differential expression analysis of RNA-seq data. Genome biology 11, R25 (2010).

54. Robinson, M. D., McCarthy, D. J. \& Smyth, G. K. edgeR: a Bioconductor package for differential expression analysis of digital gene expression data. Bioinformatics 26, 139-140 (2010).

55. Law, C. W., Chen, Y., Shi, W. \& Smyth, G. K. voom: Precision weights unlock linear model analysis tools for RNA-seq read counts. Genome biology 15, R29 (2014).

56. Chen, Y., Lun, A. T. \& Smyth, G. K. From reads to genes to pathways: differential expression analysis of RNA-Seq experiments using Rsubread and the edgeR quasi-likelihood pipeline. F1000Research 5, 1438 (2016).

57. Benjamini, Y. \& Hochberg, Y. Controlling the false discovery rate: a practical and powerful approach to multiple testing. Journal of the Royal Statistical Society. Series B 57, 289-300 (1995). 


\section{Acknowledgements}

The authors thank Drs. Thomas E. Curry Jr. and Patrick Hannon for their critical reading of the manuscript. Supporting Grants: P01 HD71875, R01 HD096077, and R03 HD095098.

\section{Author contributions}

S.L.T. and M.J. were involved in research design; S.L.T., H.J., Y.C., M.J. were involved in data acquisition; S.L.T., H.J., I.T., T.T., Y.Y., C.K., M.J. were involved in generating mutant mice; S.L.T., H.J., Y.C., and M.J. were involved in data analysis; S.L.T., H.J., Y.C., C.K., M.J. were involved in article drafting and/or revision.

\section{Competing interests}

The authors declare no competing interests.

\section{Additional information}

Supplementary information is available for this paper at https://doi.org/10.1038/s41598-020-64257-0.

Correspondence and requests for materials should be addressed to M.J.

Reprints and permissions information is available at www.nature.com/reprints.

Publisher's note Springer Nature remains neutral with regard to jurisdictional claims in published maps and institutional affiliations.

(c) (i) Open Access This article is licensed under a Creative Commons Attribution 4.0 International License, which permits use, sharing, adaptation, distribution and reproduction in any medium or format, as long as you give appropriate credit to the original author(s) and the source, provide a link to the Creative Commons license, and indicate if changes were made. The images or other third party material in this article are included in the article's Creative Commons license, unless indicated otherwise in a credit line to the material. If material is not included in the article's Creative Commons license and your intended use is not permitted by statutory regulation or exceeds the permitted use, you will need to obtain permission directly from the copyright holder. To view a copy of this license, visit http://creativecommons.org/licenses/by/4.0/.

(c) The Author(s) 2020 